\title{
Ice Crystal Icing Physics Study using a NACA 0012 Airfoil at the National Research Council of Canada's Research Altitude Test Facility
}

\author{
Peter M. Struk * \\ Michael C. King ${ }^{\dagger}$ \\ NASA Glenn Research Center, Cleveland, OH, 44135 \\ and \\ Tadas P. Bartkus ${ }^{\ddagger}$ \\ Jen-Ching Tsao ${ }^{\S}$ \\ Ohio Aerospace Institute, Cleveland, $\mathrm{OH} 44135$ \\ and \\ Dan Fuleki** \\ Martin Neuteboom ${ }^{\dagger \dagger}$ \\ Jennifer LY Chalmers $\$$ \\ National Research Council of Canada, Ottawa, Ontario, K1A OR6
}

\begin{abstract}
This paper presents results from a study of the fundamental physics of ice-crystal ice accretion using a NACA 0012 airfoil at the National Research Council of Canada (NRC) Research Altitude Test Facility in August 2017. These tests were a continuation of work which began in 2010 as part of a joint collaboration between NASA and NRC. The research seeks to generate icing conditions representative of those that occur inside a jet engine when ingesting ice crystals. In this test, an airfoil was exposed to mixed-phase icing conditions and the resulting ice accretions were recorded and analyzed. This paper details the specific objectives, procedures, and measurements which included the aero-thermal and cloud measurements. The objectives were built upon observations and hypothesis generated from several previous test campaigns regarding mixed-phase ice-crystal icing. The specific objectives included (A) ice accretions under different wet-bulb temperatures, $(B)$ investigations of steady-state ice shapes previously reported in the literature, $(C)$ total water content variations in search of a threshold for accretion, and (D) probe characterization related to measuring melt fraction which is important to characterize the mixed-phase condition. The resulting ice accretions and conditions leading to such accretions are intended to help extend NASA's predictive iceaccretion codes to include conditions occurring in engine ice-crystal icing.
\end{abstract}

\footnotetext{
* Aerospace Engineer, Icing Branch, 21000 Brookpark Road, AIAA Senior Member

$\dagger$ Aerospace Engineer, Icing Branch, 21000 Brookpark Road

* Senior Research Scientist, Icing Branch, 21000 Brookpark Road, AIAA Member

$\S$ Principle Research Scientist, Icing Branch, 21000 Brookpark Road, AIAA Associate Fellow

** Project Manager, 1200 Montreal Rd., Gas Turbine Laboratory, Building M7, AIAA Senior Member

† Research Officer, 1200 Montreal Rd., Gas Turbine Laboratory, Building M7

$\$$ Research Officer, 1200 Montreal Rd., Gas Turbine Laboratory, Building M7 


\section{Nomenclature}

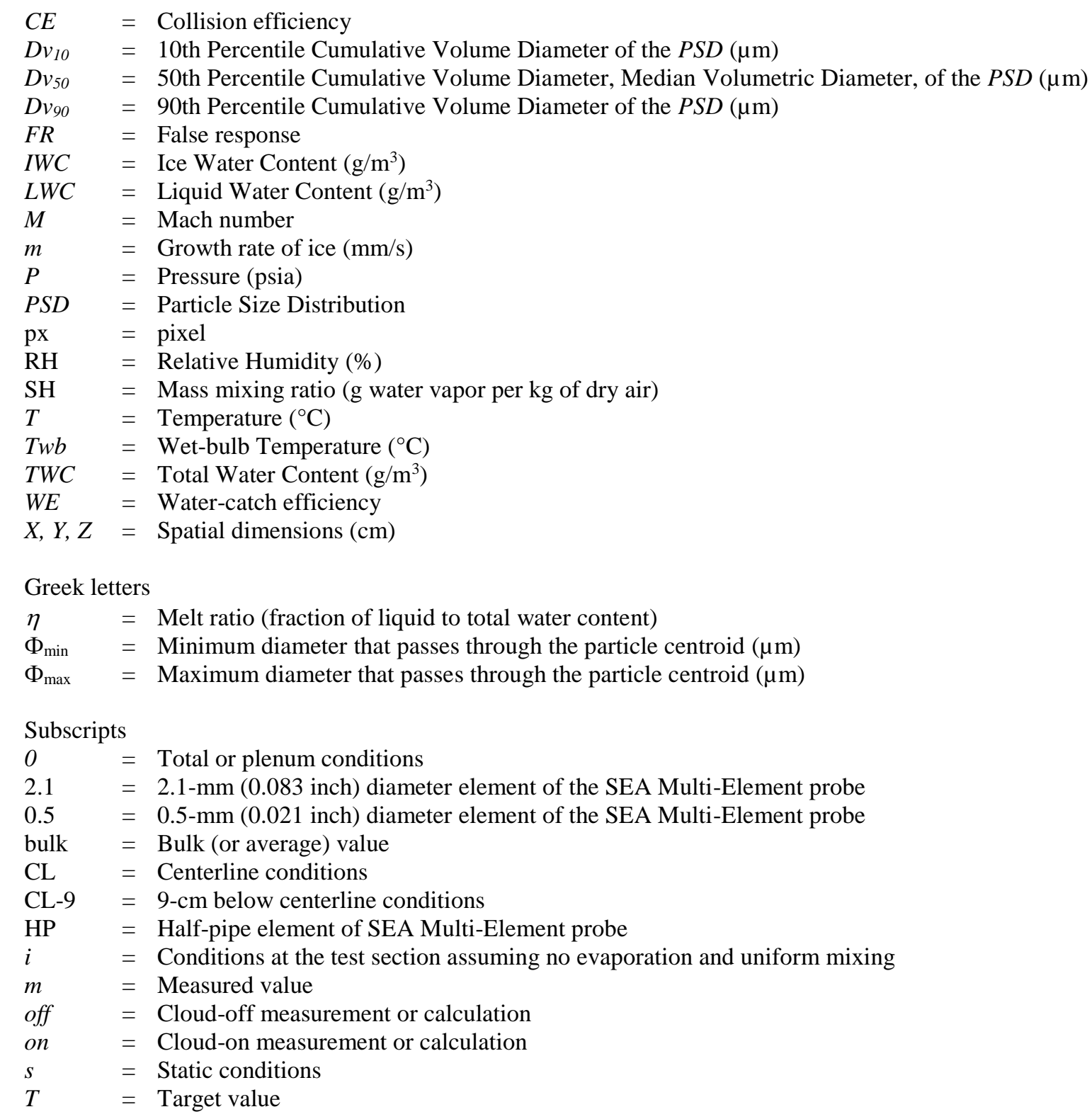

\section{Introduction}

Due to numerous engine power-loss events associated with high-altitude convective weather, ice accretion within an engine due to ice-crystal ingestion is being investigated collaboratively by the National Aeronautics and Space Administration (NASA) and the National Research Council (NRC) of Canada. The investigations focus on the fundamental physics associated with ice accretion. This investigation examines ice accretions on an airfoil test article exposed to ice-crystal and mixed phase conditions similar to those believed to exist in core compressor regions of jet engines. The conditions were generated using the NRC's Research Altitude Test Facility (RATFac) which can introduce ice particles (and/or supplemental liquid water droplets) into an airflow in warmer than freezing conditions and various pressures. The partially melted ice particles and supplemental liquid water, if used, produce a mixedphase condition which impinges on the airfoil test article. Under certain aero-thermal conditions and melt ratios (i.e. 
fraction of liquid water ${ }^{*}$ to total ice and liquid water), ice accretions occurred on the airfoil. The ice accretion data is being used to help extend predictive ice-accretion codes, which were originally designed for supercooled liquid water only, to include the mixed-phase ice crystal conditions occurring in engine icing. This paper reports on a test entry which took place at the NRC RATFac in August 2017 and built upon several previous test campaigns at that test facility.

\section{Background}

The first series of experiments ${ }^{1}$ by NASA and NRC at the RATFac ${ }^{2}$ were conducted in November 2010 . These experiments utilized a single wedge-type airfoil designed to facilitate fundamental studies while retaining critical features of a compressor stator blade or guide vane. The airfoil was placed in the NRC Cascade wind tunnel of the RATFac for both aerodynamic and icing tests. Icing tests were performed at various Mach numbers, altitudes, temperatures, and melt ratios. In these tests, the ice appeared well adhered to the surface when at higher altitude (lower air pressure) while at lower altitude (higher air pressure tests) the accretions were limited to a small area around the leading edge. The icing behavior at high and low pressure appeared to be correlated with the wet-bulb temperature, which was estimated to be above $0^{\circ} \mathrm{C}$ in the lower altitude tests and below $0^{\circ} \mathrm{C}$ in tests at higher altitude, the latter enhanced by more evaporative cooling of water. Later tests ${ }^{3}$ conducted in 2011 confirmed that wet-bulb temperature is a good indicator for the potential for icing.

Although wet-bulb temperature may be a good indicator for the type of icing observed, other factors can influence when icing occurs. These include the droplet or particle catch efficiency (governed by geometry, flow field, particle size, etc.) and water loading and state. Regarding the water state, all previous studies show that the presence of liquid water is required for ice buildup to occur. Furthermore, Mason et al. ${ }^{4}$ hypothesized that there is an optimum ratio of water to ice that maximizes ice accretion for a given water loading which was later experimentally demonstrated by Currie et al. ${ }^{5}$.

A challenge in these experiments is to independently vary the melt ratio and wet-bulb temperature as the wetbulb temperature also governs the amount of natural melting ${ }^{\dagger}$ that occurs of the ice-crystal cloud. The wet-bulb temperature is adjusted in the experiments by varying the temperature, pressure, and the specific humidity of the airflow. For melting to occur, the wet-bulb temperature needs to be warmer than freezing somewhere along the particle trajectory before reaching the test section. Furthermore, the different temperatures, pressures, and humidity values result in varying cloud evaporation which in turn result in varying amounts of liquid and ice water contents at the test section.

Measuring the fraction of liquid water content in a mixed-phase cloud is challenging. The NRC facility has been using a hot-wire probe called Multi-Element Probe developed by Science Engineering Associates (SEA) to determine both the liquid water content $(L W C)$ and total water contents $(T W C)$. The ratio of $L W C$ to $T W C$ is the melt ratio. The SEA Multi-Element Probe has three elements: one for measuring $T W C$ and two for measuring $L W C$. Data from the previous tests indicate that the $T W C$ is under measured in ice-crystal conditions using the TWC sensor of the SEA Multi-Element Probe. Furthermore, the $L W C$ elements are sensitive to ice-water content (IWC) in mixed-phase causing a small "false response" on the sensor. The present study attempts to decouple the $L W C$ and $I W C$ signals by conducting some characterization of the SEA Multi-Element Probe. In addition, NRC has developed and tested a new compact isokinetic probe (CIKP) ${ }^{6}$ specifically designed to measure $T W C$ in mixed-phase and ice crystal conditions. The CIKP was incorporated into the current test program.

During all the previous testing, air temperature and humidity measurements showed changes at the test section when the cloud was active compared to when the cloud was off. The most recent joint NASA and NRC test ${ }^{7}$ in March 2012 included a traversable total air temperature (TAT) \& relative humidity $(\mathrm{RH})$ probe $^{8}$ which allowed measurements at tunnel centerline. Subsequent modelling showed that a decreasing air temperature was due to the energy exchange from the partial evaporation of the cloud ${ }^{9-11}$. The temperature change was sometimes as much as several degrees Celsius, which is significant for icing tests, and measurements of the cloud-on conditions are continued to the present testing.

In 2013, Currie et al. ${ }^{12}$ reported ice accretions that reached a steady-state size during a continuous exposure to a mixed-phase icing cloud. The accretions occurred on an axisymmetric test articles with a hemispherical forebody and

\footnotetext{
* Note that the liquid water can come from melted ice crystals or supplemental liquid water.

$\dagger$ Natural melting refers to test conditions where supplemental liquid water in not added to increase the liquid water content beyond what occurs naturally due to the particle trajectory through the engine or facility.
} 
were later observed on test articles with a conical and crowned cylinder forebody. ${ }^{5}$ Currie attributed the steady-state ice shape to a balance between accretion and erosion and developed a corresponding semi-empirical model of the accretions. The model introduced a concept called 'sticking efficiency', which is the fraction of an impinging mixedphase water mass flux that is retained on the surface. The model treats the accretion process as strictly a sticking phenomenon, ignoring heat transfer, phase change, runback and other location-dependent effects commonly associated with supercooled liquid water icing. In 2014, Tsao et al. ${ }^{13}$ presented a thermodynamic model of ice-crystal icing which included some of these other factors but looked only at the stagnation point. Both models require the specification of a mass loss term which preliminary estimates suggest losses that can exceed $90 \%$ of the incoming mass. Presently, erosion is evaluated empirically due to the lack of an erosion model for mixed-phase icing. Previous results from Knezevici et al., ${ }^{14,}{ }^{15}$ Currie $^{16}$ et al., as well as erosion models from non-icing fields, which are also referenced in Currie ${ }^{16}$, suggest that erosion factors include particle size, impingement angle, and velocity, as well as the mechanical properties of the erodent. The present study sought to replicate the conditions that resulted in steadystate accretion as well as vary both particle size and velocity to add further data to the limited available dataset in mixed-phase icing. Furthermore, Tsao's model predicted a minimum ice-water loading threshold below which there was sufficient heat to melt the incoming ice resulting in no accretion - this model prediction was examined during the present testing.

The NACA 0012 used in the present study was selected as a test article due to its well understood characteristics in supercooled water icing. This test article was first used by NASA and NRC in joint testing conducted in 2012. ${ }^{17}$ During the 2012 testing, the NACA 0012 test article was mounted horizontally and spanned the entire width of the Cascade wind tunnel. The intent was to record images of the ice accretions and later extract ice thickness and accretion profiles. However, water and ice flowing back on the tunnel walls and windows would cause ice to accrete in greater thickness at the wall/window and airfoil interface obscuring images of the ice at the desired midspan location. For the present tests, the NACA 0012 airfoil was mounted in the vertical orientation as shown in Fig. 1. The mounting interfaces for the airfoil are downstream of the leading edge to minimize window obscuration of the leading edge during testing.

\section{Experimental Objectives}

The objectives of the testing presented in this paper are summarized in this section. The test matrix with target aerothermal flow and cloud conditions is shown in Table 1 . The table also references the section letters (A, B, C, and D) below to allow cross-referencing a test point number to a particular objective. The overall goal of this study was to acquire data on a well characterized model (NACA 0012) and cloud for improved model predictions. This study sought to overcome some of the challenges outlined in the background section as further described in the detailed objectives below.

\section{A. Humidity $(T w b)$ Sweep}

A primary objective was to examine the effect of varying humidity, hence wet-bulb temperature $(T w b)$ on the cloud properties and resulting ice accretion. Two velocities and particle size distributions were examined with otherwise constant total pressure, total temperature, and TWCi. The humidity is varied to achieve a range of $T w b_{0}$ from above to near freezing $\left(T w b_{0}=6,3,2\right.$, and $\left.0^{\circ} \mathrm{C}\right)$ similar to Currie. ${ }^{12}$ Here the " 0 " subscript refers to a wet-bulb temperature calculated using total temperature, total pressure, and the specific humidity at the test section. Humidity variation is also the primary method to vary the natural melting of ice with higher $T w b_{\mathrm{S}}$ resulting in more melt - here the subscript "S" refers to wet-bulb temperature calculated using static temperature and pressure (with the same test section specific humidity). The static temperature and pressure are generally the conditions felt by a particle entrained in a moving flow. The current testing sought to maintain a constant $T W C$ at the test section by using dedicated calibration sprays. The injected ice rate is calibrated such that the CIKP measures approximately the same TWC for each velocity and particle size at a given $T w b$. This data is intended for future comparisons against model predictions of both tunnel conditions and ice accretion.

\section{B. Investigate Steady-State Ice Shapes}

Using a NACA 0012 airfoil, another test objective was to examine conditions where ice accretions reached a steady-steady size under continuous cloud exposure as observed by Currie. ${ }^{5,12}$ Steady-state ice accretions suggest that accretion growth is offset by an ice loss mechanism such as erosion. Using a test article with a hemispherical fore 
body, Currie observed accretions that reached a steady-state conical shape during a continuous icing exposure. These steady-state accretions occurred at a Mach numbers of 0.25 , values of $T W C$ of $\sim 8 \mathrm{~g} / \mathrm{m}^{3}$, and a particle size distribution reported as $D v_{10}=31 \mu \mathrm{m}, D v_{50}=57 \mu \mathrm{m}$, and $D v_{90}=126 \mu \mathrm{m}$. However, only continuous growth (i.e. no accretions that reached a steady-state size) occurred at higher Mach numbers of $M=0.47$ and .59 and particle sizes reported as $D v_{10}=19 \mu \mathrm{m}, D v_{50}=28 \mu \mathrm{m}$, and $D v_{90}=44 \mu \mathrm{m} .{ }^{16}$ To compare against Currie's results, tests at Mach numbers of $M=0.4$ and smaller particle sizes were conducted in the present study. The Mach number could not be increased much beyond $\sim 0.4$ due to blockage of the airfoil model choking the mass flow at the test section. Reproducing such steady state accretions on the well-characterized NACA 0012 will allow better estimates of the erosion losses.

\section{Variation of TWC}

A third objective was to examine the effect of varying $T W C$ while maintaining the same aerothermal conditions (cloud off) on the resulting cloud properties and ice accretion. Work by $\mathrm{Tsao}^{13}$ suggests that there exists a minimum $T W C$ threshold to have ice formed on the surface by the accumulation of un-melted ice crystals. Below this threshold value, sufficient heat is available to melt the incoming ice to prevent accumulation. Such a threshold was predicted in what Tsao called the "melting-dominated" regime. The present testing attempted to experimentally verify this threshold and provide data to compare against existing models of ice crystal accretion.

\section{Multi-element response characterization in ice-crystals}

The fourth objective of these tests was to characterize the multi-element response to ice-crystals. As noted in the background, previous testing has shown that the Multi-Element probe under-measures the TWC in mixed-phase and ice crystal conditions due to mass loss from the heated element before complete evaporation occurs. Also, the $L W C$ sensors experience a "false response" signal due to the presences of ice crystal. Furthermore, some of the melted water on the particle surface may not transfer to the heated element (i.e. splash away) hence under reporting the $L W C$. The purpose of the calibration test points was to measure some of those losses. The SEA Multi-Element probe and CIKP were exposed to a purely glaciated cloud in sub-freezing conditions. Data from these tests were used to calculate the false response of the $L W C$ sensors and applied as a correction factor as described in the analysis method section below. The CIKP data is expected to be a more accurate measurement of $T W C$ and will be used without correction. Although not done in this study, comparisons of the TWC measured with the Multi-Element probe and CIKP could be made to determine a correction factor which can be helpful to adjust historical data sets that share similar conditions to tests reported in this paper.

\section{Experimental Description}

This study utilized a NACA 0012 airfoil mounted vertically in the test section of the Cascade rig wind tunnel placed inside the NRC RATFac. The airfoil had 15 thermocouples to measure surface temperature (Fig. 2). Video images captured the ice accretions on the airfoil from which ice shape information was extracted. The flow aerothermal measurements included total and static pressure, total temperature (both with and without the presence of the cloud), and humidity. For the cloud, the $L W C, T W C$, and particle size distribution (PSD) were measured. This section provides details on the facility, hardware, and measurements.

\section{A. Test Facility}

The tests were conducted in the Cascade wind tunnel at the NRC RATFac. Numerous publications provide details of the facility ${ }^{2}$ and general experimental setup ${ }^{7}$ and only a short overview is provided here. The test cell is divided into hot and cold sides by a partition. An ice grinder system, located on the cold side, injects ice particles in the airflow while the rig side contains the Cascade wind tunnel. A flow of cold $\left(\sim-15^{\circ} \mathrm{C}\right)$ and dry $\left(\sim-50^{\circ} \mathrm{C}\right.$ dew point $)$ air with the entrained ice particles passes from the cold side through an injection duct and is mixed with warmer air entering the Cascade wind tunnel. The temperatures and pressures in the facility were adjusted to obtain the desired total temperature and pressure at the test section. The relative humidity $(R H)$ of the mixed airflow can be controlled by varying the humidity of the altitude chamber (warm) air with a humidification system. Varying the humidity controls $T w b$, which in turn controls the degree of natural melting of the ice crystals. Supplemental water can be injected from

\footnotetext{
${ }^{*}$ The specific cases targeted to be replicated in this work were scans $1123,1139,1286$ from Currie et al. ${ }^{11}$
} 
a set of spray nozzles to raise $L W C$, if required. The grinder can be configured to deliver different particle size distributions.

\section{B. Airfoil Model}

Figure 1 shows the NACA 0012 test article mounted in the Cascade wind tunnel. The airfoil has a chord length of $26.67 \mathrm{~cm}$ (10.5 inches) and span of $13.21 \mathrm{~cm}$ (5.20 inches) not including the mounting fairings (shown in yellow in Fig. 1). The hollow air cavity is $8.26 \mathrm{~cm}$ (3.25 inches) spanwise with the side profile dimensions shown in Fig. 1. The main airfoil body is made from the titanium alloy, Ti-6Al-4V. The mounting fairings are made from 6061-T651 aluminum. The airfoil is limited to a $0^{\circ}$ angle of attack when mounted in the tunnel. The airfoil has 14 type $\mathrm{K}$ thermocouples embedded in the surface as shown in Fig. 2 with positions reported relative to leading edge at midspan. An additional thermocouple (\#15) is located within the center model on the metal surface at the aft end of the hollow air cavity.

\section{Video}

During the experiment, video cameras recorded three views of the airfoil: (1) a spanwise view; (2) a perspective view looking at the leading edge at an oblique angle; and (3) a profile backlit view (Fig. 3). The three views combined allow determination of the shape and extent of ice accretion. The spanwise view data allows measuring the leadingedge ice accretion growth against time and overall ice-thickness uniformity across the span. The front perspective view allows observation of the extent of icing. The profile backlit view allows measuring the $2 \mathrm{D}$ ice shape. The ideal 2D measurement is at the midspan as this is the location best characterized by the SEA Multi-Element and CIKP probes. Measurement of the 2D ice shape requires that the windows remain clear of ice and water. Images with scales were taken for all views and zoom configurations tested to establish a relationship to convert pixels to a physical dimension.

\section{Aerothermal Measurements}

The NRC uses several probes for characterization of the test section flow condition. A probe called the Kiel probe (also called the $P_{0} \& T_{0}$ probe) is used to measure total pressure and temperature during cloud-off conditions. A rearward facing total temperature probe, which also serves as an inlet for a humidity measurement (hence it is called the $T A T \& R H$ probe), takes measurements during both cloud-off and cloud-on operations. A small suction is created on this probe which is routed to a hygrometer for a humidity measurement. More details on the TAT \& RH probe can be found elsewhere. ${ }^{8}$ When the cloud is activated, a temperature change $(\Delta \mathrm{T})$ and humidity change is typically measured by the $T A T \& R H$ probe. That $\triangle \mathrm{T}$ is applied to the dry (cloud off) measurement from $P_{0} \& T_{0}$ probe to establish the total temperature at the test section with the cloud on, $T_{0, o n}$. The $T A T \& R H$ probe, which is visible in Fig. $1(\mathrm{~F})$, is traversable but was generally used to measure the centerline conditions at the test section with the cloud on. Finally, a pressure measurement is made using a static tap on the upper wall of the tunnel, upstream of the test section inlet. This measurement is used to calculate tunnel Mach number but can become corrupted if there is accretion on the wall and/or heavy liquid water content. This pressure tap can be purged at the end of such points to clear the line.

\section{E. Cloud Measurements}

1. Multi-Element Probe

The SEA Multi-Element probe ${ }^{18-20}$, seen in Fig. 1G, makes measurements of the total and liquid water contents approximately $36 \mathrm{~cm}$ (14 in.) upstream of the airfoil leading edge. The probe provides three different water-content measurements: a total water content measurement using a half-pipe shape hot-wire element $\left(T W C_{m, H P}\right)$ and two measurements of liquid water content, $L W C_{m, 2.1}$ and $L W C_{m, 0.5}$, from two different diameter hot-wire elements, 2.1-mm and 0.5-mm, respectively. Unless otherwise noted, the reported Multi-Element measurements are 30-second averages of the data and are not adjusted for collision efficiency. For the current testing, the SEA Multi-Element probe was traversable only from $\mathrm{X}=0$ to $+6.6 \mathrm{~cm}$ (2.6 in.") and was inserted from the other side of the duct compared to prior testing in order to accommodate the CIKP (Fig. 1F). 


\section{Compact Iso-kinetic Probe (CIKP)}

The CIKP, seen in Fig. 1F, is designed to measure TWC in glaciated and mixed-phase icing conditions. The principle of operation for the probe is to ingest cloud hydrometeors (i.e. particles of liquid water and ice) and air in an isokinetic fashion with minimal water mass loss. The hydrometeors and background air flows through an evaporator. The resulting total humidity of the background air plus evaporated water is then measured before the airflow is vented out of the probe. The inlet for the CIKP was approximately $19 \mathrm{~cm}(7.5 \mathrm{in}$.) upstream of the test article leading edge. The TWC from the ingested hydrometeors is then calculated by subtracting an independent measurement of background humidity using the $T A T \& R H$ probe whose inlet was approximately $12.7 \mathrm{~cm}(5 \mathrm{in}$.) upstream of the test article leading edge. The CIKP is traversable between $+/-6.6 \mathrm{~cm}$ (2.6 inches) horizontally and $+/-12.7 \mathrm{~cm}$ (5 inches) vertically relative to the centerline of the test section

\section{Particle measurement}

Particle measurements were made with three different instruments during this test: (1) the NRC Particle Imaging Velocimetry (PIV) system ${ }^{21,22}$ and the modular versions of the High Speed Imaging (HSI) and Phase-Doppler Interferometer (PDI) probes from Artium Technologies, Inc. ${ }^{23}$ The instruments, which use lasers to probe the flow non-intrusively, made measurements just upstream of the bellmouth as seen in Fig. 4. The sample volume for the PIV and HSI/PDI systems was approximately $8 \mathrm{~cm}(3 \mathrm{in}$.$) and 31.7 \mathrm{~cm}$ (12.5 inches), respectively, upstream of the bellmouth entrance at the tunnel centerline. The distance from the bellmouth entrance to the test section was 102.1 $\mathrm{cm}$. The PDI data was used primarily for $L W C$-only sprays and results from those measurements are not included in this report.

\section{F. Test Conditions and Procedure}

For setting test conditions, a set of target aero-thermal and cloud conditions were established for the test section (Table 1). The test section is a plane just upstream of the airfoil leading edge. The aero-thermal conditions are the total pressure $\left(P_{0}\right)$, total temperature $\left(T_{0}\right)$, Mach number, and humidity using the mass mixing ratio which is also referred to as the specific humidity $(S H)$. The wet bulb temperature is adjusted by varying the humidity of the flowing air for a fixed $T_{0}$ and $P_{0}$. Lower humidity results in lower wet-bulb temperatures but also more evaporation. The target conditions referred to "cloud-off" conditions, and use the subscript 'off', since these do not account for changes due to thermal interaction with the cloud. During cloud-on testing, the changes in aerothermal conditions, specifically temperature and humidity, were measured and referred to as the "cloud-on" conditions using the subscript 'on'.

The cloud parameters are the bulk ice water content $\left(I W C_{i}\right)$, ice particle volumetric diameter percentiles $\left(D v_{10}\right.$, $D v_{50}$, and $\left.D v_{90}\right)$, bulk supplemental liquid water content $\left(L W C_{i}\right)$, and supplemental liquid water content median volumetric diameter $\left(M V D_{i}\right)$. The $I W C_{i}$ and $L W C_{i}$ are defined based on the ice and water feed rate, respectively, using the test section area assuming a uniform water distribution and no evaporation. The target ice particle sizes were based on prior NRC characterizations for a given grinder setting although recent changes to the grinder system necessitated measurement of the actual $P S D$. Similarly, the target droplet sizes for the $L W C i$ were based on prior NRC characterizations and actual $P S D$ measurements were made when able.

Dedicated "calibration" sprays were performed to determine the facility ice and/or supplemental water setpoints to achieve the desired $T W C_{m}$. The actual setpoints are shown in Table 2 . The calibration sprays typically were performed only when the target $T W C_{m}$, flow velocity, or particle size changed. Variations in $T W C_{m}$ due to different target test-section humidity values were accepted since previous experience by NRC suggested the $T W C_{m}$ variation would be small.

A typical ice accretion test would begin with the $P_{0} \& \mathrm{~T}_{0}$ probe at the tunnel centerline to record the facility steady-state, cloud-off, conditions just prior to cloud activation. The $P_{0} \& \mathrm{~T}_{0}$ probe was then retracted and the SEA Multi-Element probe, and occasionally the CIKP probe, inserted to the flow centerline for a short period of time to record the zero- $T W C$ power values. Once the probes were removed, video recording was started and the icing cloud activated. Ice accretion was performed for either a fixed time or up to the point of window obscuration. Without turning off the icing cloud, the CIKP and then SEA Multi-Element probe were inserted into the flow centerline for water content measurements and then retracted. Subsequently, the $T A T \& R H$ probe was elevated from its parked position (humidity inlet approximately $9 \mathrm{~cm}$ below centerline) to the tunnel centerline ${ }^{*}$. Finally, the cloud was turned

* The TAT \& RH probe traverse malfunctioned early in the test program preventing some centerline measurements from being taken. For those cases, centerline measurements are left as blanks in the data tables. 
off with the $T A T \& R H$ probe at the centerline to measure any changes in the cloud-off temperature and humidity after the test. The test would end with the $T A T \& R H$ probe being retracted and the $P_{0} \& T_{0}$ probe being reinserted into the flow centerline.

\section{Analysis Method}

Except where noted otherwise, the measurements of aerothermal and cloud data presented in this paper are typically 30-second averages of the data. The "cloud-off" value is calculated just prior to cloud activation while the "cloud-on" value is calculated using the last 30-seconds of when a particular probe was at the flow centerline. There was approximately a 6-second lag from when the cloud activated and the facility "ICEON" parameter indicated that the cloud was active - this was determined by comparing model thermocouple data with the facility ICEON parameter. This lag was factored into the analysis so that "cloud-off" data was strictly calculated with the cloud off.

\section{A. Total Water Content / CIKP Analysis Method}

The CIKP measured total water content, $T W C_{m}$, where the subscript $m$ denotes a measured value. The CIKP was moved to the flow centerline during a calibration spray or at the end of an accretion spray. As the probe moved towards the centerline, the $T W C_{m}$ typically increased. A running 30 -second average of the $1 \mathrm{~Hz}$ data usually plateaued to a near steady reading after about 30-seconds. Occasionally, the $T W C_{m}$ suddenly increased during the averaging period perhaps due to the ingestion of a large ice particle. The increases could be very rapid, within 1 to 2 seconds, and significantly increasing the running average for the next 30 seconds. In addition, the $T W C_{m}$ also rapidly dropped for a few tests for unknown reasons. To minimize these effects, the values shown in Table 2 are the average of the last 15 -seconds of the raw (non-averaged) data while the probe was at centerline, and this value represented the $T W C_{m}$ value for that test. For cases where there was an abrupt shift in the data (denoted with an asterisk next to the CIKP measurement in Table 2), the $T W C_{m}$ was manually averaged during periods where the 15 -second runningaverage data was steady after the probe was established at centerline.

\section{B. Multi-element False Response Characterization}

The false response $(F R)$ of the SEA Multi-Element $L W C$ sensors to ice crystals was measured using a glaciated cloud for 4 different conditions including Mach numbers of 0.25 and 0.4 and both PSDs used in the experiment (a small and large $P S D$ described further below). The target total temperatures were $-5^{\circ}$ or colder (see Table 1 for actual conditions tested). The $0.5-\mathrm{mm}$ and $2.1-\mathrm{mm}$ diameter element $L W C$ measurements as a percent of $T W C$ measured by the CIKP are shown in Fig. 5. The SEA Multi-Element measurements were corrected ${ }^{24}$ for collision efficiency based on the target MVD. The collision efficiency and all the measurement values used for the false response calculation are shown in Table 3.

Figure 5 shows the false response was larger for the $0.5-\mathrm{mm}$ element compared to the $2.1-\mathrm{mm}$ element for the conditions tested. The false response trend with Mach number shows different behavior based on particle size. With the smaller size $P S D$, the false response decreased when the Mach number increased from 0.25 to 4 . With the larger size $P S D$, the false response increased with the corresponding Mach number change.

\section{Determining melt ratio}

The melt ratio, $\eta$, or ratio of liquid to total water content, Eq. (1), is estimated from the measured values of $L W C_{m}$ and $T W C_{m}$. The subscript $m$ is used to denote a measured value of water content whereas parameters without a subscript denote an estimate of the actual values. For total water content, the unmodified measurement from the CIKP is used (i.e. $T W C_{m, C I K P}=T W C$ ) and is assumed to be a simple sum of the $L W C$ and $I W C$ as shown in Eq. (2). For liquid water content, the measurement from the Multi-Element probe, either $L W C_{m, 2.1}$ or $L W C_{m, 0.5}$, is a combination of both impinging liquid and ice. In a purely glaciated cloud, the impinging ice crystals result in a non-zero measurement on the $L W C$ elements which is termed a false response. Here, the false response $(F R)$ is assumed to be proportional to $I W C$ as shown in Eq. (3). In a purely liquid cloud, the measurement from $2.1-\mathrm{mm}$ and $0.5-\mathrm{mm}$ cylindrical elements is less than what is measured by the CIKP ${ }^{9}$. Hence a water-catch efficiency (WE) term is applied

\footnotetext{
* The subscripts 2.1 and 0.5 denote the $2.1-\mathrm{mm}$ and $0.5-\mathrm{mm}$ diameter cylindrical element of the SEA MultiElement Probe, respectively.
} 
to the actual $L W C$ as seen in Eq. (3). In addition, the smallest water and ice particles may miss the hot-wire element altogether which is accounted for by the collision efficiency, $C E$, calculated as reported by Struk ${ }^{24}$. Estimates of $L W C$ and $I W C$ are then calculated by solving Eq. (2) and (3) simultaneously. The coefficients $F R_{2.1}$ were measured during testing, as describe previously, and are used in the calculations. The coefficients $W E_{2.1}$ were not able to be measured during testing since complete melting of the initially glaciated cloud was not possible - for this analysis, $W E_{2.1}$ was set to $0.75+/-33 \%$ for all conditions based on data reported by Struk ${ }^{25}$ taken at the NASA Propulsion Systems Laboratory facility showing this parameter varied from 0.5 to $0.7^{*}$.

$$
\begin{gathered}
\eta=\frac{L W C}{T W C}=\frac{L W C}{L W C+I W C} \\
T W C_{m, I K P}=T W C=L W C+I W C \\
L W C_{m, 2.1}=C E_{2.1}\left(W E_{2.1} \cdot L W C+F R_{2.1} \cdot I W C\right)
\end{gathered}
$$

An uncertainty analysis was performed on the calculated melt ratio. Substituting Eqs. (2) and (3) into Eq. (1) and rearranging yields Eq. (4). Taking the partial derivative of $\eta$ with respect to each of the parameter yields the sensitivity of that equation to variation in that parameter. Multiplying the partial derivative expressions (i.e. the sensitivity coefficients) by the estimated uncertainty of each parameter (Table 4) provides a measure of the melt-ratio uncertainty due to that parameter. Combining these uncertainties using a root-sum-square method ${ }^{26}$ produces an overall uncertainty estimate for $\eta$ which is reported with the melt ratio in Table 2. Examination of the melt ratios in Table 2 show the uncertainty increase as $\eta$ increases. This occurs because the parameter $W E$ becomes more important at higher LWC and currently this is the least understood parameter in the calculation (in this paper, the uncertainty for $W E$ is estimated to be $33 \%$ based on previous results).

$$
\eta=\frac{\frac{L W C_{m, 2.1}}{C E_{2.1}}-F R_{2.1} \cdot T W C_{m, I K P}}{\left(W E_{2.1}-F R_{2.1}\right) T W C_{m, I K P}}
$$

\section{Thermocouple Analysis}

The thermocouple measurements along midspan are presented in this paper (Fig. 2). These are the most relevant measurements for 2D modelling purposes and are included so that future modelling efforts can account for the various surface temperature profiles observed in the experiment. In this section, results from a single test point are first described in detail. Subsequently, single values representing cloud on and off measurements are presented in a table format.

6 shows measurements from Test Point 3.11 during the entire cloud-on period as well as about a minute before and after. This particular test point is shown as a representative case since temperature trends were similar between different tests. Before cloud activation, all the thermocouples measured a temperature close to the total air temperature. Once the cloud was activated (at $\mathrm{t}=0$ seconds), the leading edge thermocouple (TC\#3) dropped to near $0^{\circ} \mathrm{C}$ within about 7 seconds due to the impingement of mixed-phase water. This quick temperature drop was typical of every test. Downstream thermocouples took longer to cool down with TC\#6 and \#7 taking 43 and 94 seconds, respectively, to reach $0^{\circ} \mathrm{C}$ in the example shown in Fig. 6. For this case, thermocouples further aft reached steady state temperatures above freezing: $0.8^{\circ} \mathrm{C}, 1.7^{\circ} \mathrm{C}$, and $2.3^{\circ} \mathrm{C}$ for TC\#10, TC\#13, and TC\#14, respectively. These values are 30 second averages of the temperature measurement from 275 to 305 seconds after cloud activation. In this test, the CIKP was inserted into the flow starting at 305 seconds and thermocouple measurements were no longer analyzed since the upstream probe could affect the surface temperature. TC\#15, which is wall temperature measurement inside the airfoil model, did not reach steady state for this test. For this test, TC\#15 was still decreasing approximately $0.8^{\circ} \mathrm{C}$ per minute

* The $L W C$ mass loss is likely lower in the present experiment due to the lower $L W C$ values and technique used to generate mixed-phase (i.e. melting) hence the parameter $W E$ is likely higher in the present experiment than those reported by Struk ${ }^{25}$.

9

American Institute of Aeronautics and Astronautics 
based on a linear curve fit of the last 30 seconds of ice accretion. In general, this thermocouple was decreasing at rates ranging from 0.2 to $1.0^{\circ} \mathrm{C}$ per minute at the end of the ice accretion portion of the test.

Table 5 shows the cloud off and on temperature measurements for most of the test points presented in this paper. The cloud-off values are averages of the 30 seconds before cloud activation. The cloud-on values are averages of the 30 seconds before either the CIKP or SEA Multi-Element probe begin moving into the flow which represented the end of the icing test. Only midspan data is presented. Generally, the spanwise temperature variation was about $1^{\circ} \mathrm{C}$ although a few cases had variations as much as $3^{\circ} \mathrm{C}$. With the cloud active, Table 5 shows that there could be as high as a $10^{\circ} \mathrm{C}$ chord-wise temperature variation between TC\#3 and TC\#14 (e.g. Test Points 1.04, 2.00, 2.01, 2.02). However, other test points showed a difference of less than a degree between these two points (e.g. Test Points 1.08, 2.06). Other tests were somewhere in between those values. Finally, it is important to note for those modelling these results that some of the further aft thermocouples were still changing slightly (generally still cooling) at the end of the icing test and may have not reached a steady-state temperature.

\section{E. Particle size data analysis}

There were two target $P S D$ s for the ice crystal cloud used during this test, a smaller and larger PSD, and will be referred to as such in the remainder of this document. The target $P S D$ values were set to try and match some of Currie's earlier work as described in the experimental objectives section. The target distribution for the "large" $P S D$ was $D v_{10, T}=31 \mu \mathrm{m}, D v_{50, T}=57 \mu \mathrm{m}$, and $D v_{90, T}=126 \mu \mathrm{m}$. For the "small" $P S D$ the target $P S D$ was $D v_{10, T}=19 \mu \mathrm{m}$, $D v_{50, T}=28 \mu \mathrm{m}$, and $D v_{90, T}=44 \mu \mathrm{m}$. The NRC grinder system was set to the approximate target values based on previous calibrations. However, the NRC grinder system recently underwent some modifications so measurements were required to determine the actual PSDs. Furthermore, it was of interest to see how the various test conditions affected the measured $P S D$.

During this test campaign, PSD measurements were made using the NRC PIV system and the Artium Technologies, Inc. HSI and PDI system (see Fig. 4). The NRC PIV system sample volume was approximately 7-cm upstream of the bellmouth (i.e. cascade rig inlet). The HSI was used during mixed-phase testing using the grinder ice. The PDI was used to measure the LWC-only sprays from the supplemental water system and results from those measurements are not included since those test cases are not discussed in this paper. The HSI and PDI sample volume was approximately $32-\mathrm{cm}$ upstream of the bellmouth. Further description of the measurement techniques and results obtained from these probes is given below.

\section{NRC Particle Imaging Velocimetry Analysis}

NRC has developed a technique to size fast moving airborne particles using a particle imaging velocimetry (PIV) system. This technique is described elsewhere ${ }^{21}$ but the basic principle is to backlight the airflow containing the particles with a light source of even intensity, which in this case, is laser light passed through a diffuser. This produces a backlit 2D image of particles allowing for size and morphology to be characterized with a sample image shown in an inset image of Fig. 7. The light source is in line with the camera which uses a telescopic lens to create a focal plane in the cloud of particles. To avoid exposure of the camera and diffuser to altitude conditions, they are installed in insulated enclosures which maintain a sea level, room temperature environment with alignment achieved by mounting the enclosures on a common X-rail (see Fig. 4). Air knives were installed in front of the diffuser and camera enclosure windows to prevent particles or condensation from accumulating. The camera and optics for this setup had a field of view of approximately $6 \times 4.5 \mathrm{~mm}$ (width $\mathrm{x}$ height) with the focal plane approximately $50 \mathrm{~cm}$ from the camera lens, 25 $\mathrm{cm}$ from the diffuser and $7 \mathrm{~cm}$ upstream of the cascade rig inlet.

The laser has the ability to produce a very short pulse, approximately $20 \mathrm{~ns}$, so as to freeze fast moving particles which has allowed the imaging of particles traveling up to $200 \mathrm{~m} / \mathrm{s}$. This can also be configured with two lasers whose pulses can be timed to capture two images of the same particles having a known spacing in time and location. This permits the ability to measure particle velocity and 2D trajectory along the direction of the focal plane.

Using this setup and techniques outlined in Ref. 21, the particle size data for the various test points was measured and are summarized in Table 6. These distributions were produced using the NRC A2 grinder configuration which produced the range of particle size distributions by varying the operating parameters of the grinder system. The grinder operating parameters can be changed in a few seconds which allows for rapid and simplified testing of different PSD's within a limited range. Larger PSD's (e.g. up to $D v_{50}=700 \mu \mathrm{m}$ ) can be obtained with different grinder configurations but require a few hours to setup but were not required for this test campaign. 
In addition to PSD data, the $2 \mathrm{D}$ images can be used to calculate centricity $\left(\Phi_{\min } / \Phi_{\max }\right)$ and are plotted versus particle diameter, Fig. 7. The centricity can be seen to range from 0.2 to 0.9 , generally consistent across the particle size range and has a volume weighted average of 0.63 . These results are similar to those from the next smallest PSD grinder configuration, configuration A-small (1). It is important to note however, that due to pixilation, smaller particles $(\Phi<\sim 50 \mu \mathrm{m})$ will bias towards a lower centricity as detailed in the Ref. 21.

\section{Artium High Speed Imager Analysis}

The HSI is a particle sizing instrument that uses a spatial sampling technique. The HSI acquires high-resolution images of particles passing through an interrogation volume. This volume is created by focusing several laser beams on a common spatial point, illuminating particles for image capture by a CMOS camera with a long range optic, which is recording at $50 \mathrm{~Hz}$, nominally. The lasers are simultaneously pulsed with a pulse duration on the nanosecond timescale, reducing exposure times and motion blur of the images. With knowledge of the system resolution determined during setup calibration, the system can size spherical and irregularly shaped particles, and quantitative assessments of particle morphology can be made, allowing for potential identification of glaciated particles. The resolution for the HSI during the test was $3.7 \mu \mathrm{m} / \mathrm{px}$.

Prior to the test at NRC, the HSI was modified by increasing the field of view to address issues that had been encountered in previous icing tests at PSL ${ }^{23}$. The field of view increased from $640 \mathrm{px}$ by $480 \mathrm{px}$ to $1936 \mathrm{px}$ by $1216 \mathrm{px}$, giving a field of view just under $7.1 \mathrm{~mm}$ by $4.5 \mathrm{~mm}$, and the laser beams were expanded to fill the new field. This modification was done to increase misalignment tolerance due to vibration encountered in previous tests, and increase the data rate. As an unintended consequence, the image quality was dramatically reduced during sprays with very high particle concentration. Figure 8 shows a sample image taken during one such spray. The researchers were required to find a balance point for the system for each condition. Too high of setting would lead to an over-saturated image at the center, which would "wash-out" many of the particles, and too low of a setting would lead to a dark image where the gradient between the background and the particle shadow would be insufficient to identify particles. Despite these efforts, the image noise for many of the test points was unacceptably high, hindering the fidelity of the analysis.

Measurements from the Artium HSI for only select test points are included in Table 6. Due to the challenges explained in the previous paragraph, only a limited number of test points were able to be analyzed. Test point 1.04 corresponds to the larger PSD grinder setting. The measurements from the HSI for the "large" PSD were below and smaller than the PIV values - this discrepancy is likely due to the high particle concentrations obscuring the image which resulted in fewer detected particles. Test point 3.02,3.03 and 3.11 corresponded with the "small" PSD grinder setting and increasing $T W C$ target settings of 3,6 , and $10 \mathrm{~g} / \mathrm{m}^{3}$, respectively. As the $T W C$ increased, more particle obscuration occurred resulting in fewer particles detected by the probe. Despite the particle count number differences, the "small" PSD measurement results were very similar and much closer to the PIV.

\section{F. Image Analysis}

Video cameras, placed outside the flow, provided various perspectives of the airfoil to image ice accretion. The cameras produced high-definition images at resolutions of 2592 px by 1944 px. Two cameras were located orthogonally to the airfoil and were the primary instruments used to measure ice growth on the airfoil. The camera located above the tunnel viewed the airfoil down its span, recording 2D ice growth. For convenience, this orientation will be called the 2D-view (Fig. 3A).The camera located on the side of the tunnel test section viewed across the span of the airfoil, and was used to gauge the location of the maximum span-wise thickness. This view provided information on the leading-edge ice thickness and the uniformity of the growth across the span of the test article. For convenience, this orientation will be called the span-view (Fig. 3B). A third view, which imaged the airfoil from a perspective view (Fig. 3B C) was available for reference but not analyzed.

Ice shape analysis began with sequencing the recorded video into still images, capturing images at a rate of 1 image per second $(1 \mathrm{~Hz})$ using the imaging software called Avigilon Control $\mathrm{Center}^{27}$. The first frame that was captured marked the moment just prior to ice cloud activation. This clean airfoil was used as the reference position for the entire test as the edge locations of the clean airfoil were not visible once there was ice accretion on the airfoil. Since the cameras and test article were fixed, it was assumed in the analysis that the airfoil remained in that fixed location for every frame. Still images were sequenced until the ice cloud was turned off or one of the probes moved to the flow centerline upstream of the airfoil.

The sequenced still images were then imported into an image analysis program called Image ${ }^{28}$. A procedure was written in ImageJ that automated the process of tracing the ice for each frame. The procedure subsequently produced a comma-separated-value (.csv) file containing the $\mathrm{X}$-Y coordinates of the traced ice shape. The edge of the test article 
or ice was detected by using a thresholding technique. The initially colored image was converted to a grayscale image, where each pixel was assigned a value from 0 (black) to 255 (white). A threshold value was selected for each frame that distinguished between the background and the airfoil/ice. The X-Y coordinate position where pixels crossed this threshold became the edge of the ice shape. Ice collecting on the viewing windows of the tunnel wall, dark spots, and bright spots from light reflections made the automated process of distinguishing between the ice, the airfoil, and the background difficult at times. Several tests required manually pre-outlining the airfoil and ice shape to allow the automated procedure to recognize the ice/airfoil edge and produce the X-Y coordinates of the traced ice shape. When manual outlining was required, one image every 10 to 30 seconds was processed in this manner.

Scales were used to translate the number of pixels in an image to a physical length. Recorded images of a ruler and a scaled grid held next to the airfoil provided the scaling for the span-view and 2D-view respectively. Scaled values were recorded and measured at three different locations along the airfoil span using the scaled grid for the 2Dview. A scale was taken and calculated at the midspan and near the ends of the airfoil. The location of maximum ice thickness along the span determined which scale to use for the 2D-view.

Procedures were written in a program called Igor $\operatorname{Pro}^{29}$ to automate the data analysis of the ice shape X-Y coordinates. For the span-view analysis, the leading-edge ice thickness was calculated for all outlined images. The center 101-mm span of the airfoil was characterized for ice accretion. This represents the titanium span between the two strips of aluminum tape. Maximum ice thickness and midspan ice thickness were calculated for each processed image and plotted with respect to time. Ice growth data were fit to a line using a least squares regression for tests or portions of tests where (approximately) linear ice growth occurred. For tests where at least one complete shed event occurred, the ice growth rate was measured for the entire period of each growth instance. Analysis of ice shape and ice growth was not performed beyond a partial shed or if the windows became obscured due to runback water and ice.

For the 2D-view analysis, a 2D ice shape was produced for each processed image. Since the magnification of the ice shape changes at different distances from the camera (i.e. perspective effect), small ice accretions $(<2 \mathrm{~mm}$ thickness) were not visible at midspan from the 2D-view camera. Small ice accretions were hidden until the ice grew beyond this viewing limit on the airfoil. This perspective issue was problematic at the start of the test when ice accretions were small and still hidden, and in determining the extent of ice accretion chord-wise as the exact location where icing ends could not be seen in this view. In order to accurately calculate ice shape and ice thickness, this perspective along the airfoil span was taken into account. Depending on where maximum ice thickness occurred along the airfoil span, a correspondingly sized NACA0012 airfoil shape for that location on the span was appropriately projected onto the 2D-view image. Ice accretions that were traced used this projected/perspective airfoil shape as the initial clean reference position to calculate the thickness of the ice. Maximum ice thickness was calculated for each processed 2D image and plotted with respect to time. Ice growth data were fit to a line using a least squares regression for tests or portions of tests where linear ice growth occurred. In addition, the perpendicular ice thickness at each X-Y coordinate composing the test article was measured. This ice thickness was plotted as if the airfoil was unwrapped chord-wise with the leading edge of the airfoil centered at $\mathrm{X}=0$ and $\mathrm{Y}=0$.

\section{Results}

The results are presented in the same sequence as outlined in the objectives of Section III with the exception of the SEA Multi-Element characterization which has already been presented. The test conditions referred to in the text are the target conditions for $M, T_{0}, P_{0}$, and $T w b_{0}$. The as-measured conditions as well as any associated calculated results are included in the Table Section at the end of the document. Table 1 lists the aerothermal conditions while Table 2 list the cloud parameters, including estimates of the melt ratio. Finally, thermocouple measurements along the surface of the airfoil are presented in Table 5.

The ice accretion results include images of the near final ice shapes ${ }^{*}$ and select 2D accretion profiles extracted from the images presented as ice thickness versus unwrap distance from the leading edge. The ice shape analysis also included the leading edge ice thickness at midspan. A few cases show the midspan thickness data for the full test. However, the ice growth was generally linear (after a short transient) and only the slope of the line (after the short

\footnotetext{
* Occasionally, the windows would become obscured due to ice and water which prevented the final ice shape images from being captured or clearly seen. For these cases, the ice shape images shown were from earlier in the test before obscuration.
} 
transient) is included in the plot for most cases. Finally, the ice shape analysis results are only presented when the icing data were analyzable (i.e. generally symmetric, non-obscured, etc.).

\section{A. Humidity $(T w b)$ Sweep Results}

The humidity sweep tests were performed at two different Mach numbers, $M=0.25$ and 0.4 , and particle sizes (small and large $P S D s$ ). The other conditions were maintained approximately constant: $T_{0}=15^{\circ} \mathrm{C}, P_{0}=5 \mathrm{psia}$, and $T W C=8 \mathrm{~g} / \mathrm{m}^{3}$ which were selected to be consistent with Currie's prior work. ${ }^{5,12}$ In this section, the total wet bulb temperature, $T w b_{0}$, is referred to instead of humidity directly. The actual humidity values, including both cloud off and on values (these are different due to evaporation from the cloud), are shown in the Table Section. Examination of Table 1 shows a significant total temperature drop with decreasing humidity due to the significant evaporation of the cloud. For example, the temperature dropped approximately $4^{\circ} \mathrm{C}$ for Test Point $1.00\left(\mathrm{SH}_{m, \text { off }}=13.5 \mathrm{~g} / \mathrm{kg}\right)$. For Test Point 1.09 , the temperature dropped more than $16^{\circ} \mathrm{C}$ as this was the lowest humidity tested $\left(S H_{m, o f f}=2.6 \mathrm{~g} / \mathrm{kg}\right)$. An interesting observation, consistent with previous tests, is that the wet-bulb temperature change is small when comparing cloud-off to cloud-on conditions. The interested reader is directed to Bartkus et al. ${ }^{9-11}$ for some modelling work which further discusses the coupling of the cloud with the thermal conditions of the flow.

1. Mach $=0.25$, Large PSD

For $M=0.25$, only the smaller $P S D$ cases (test points 1.07 thru 1.09) are presented as the larger PSD cases (test points 1.00 thru 1.04) did not produce symmetric ice accretions. For these latter cases, the initial ice shape shifted to one side shortly after cloud activation but did not shed. From there, the ice shape grew asymmetrically to one side (see Fig. 9). It is possible that there was a small flow misalignment or non-axisymmetric ice cloud distribution in the tunnel which caused the ice shape to shift to one side early in the accretion but this could not be independently verified.

2. Mach $=0.25$, Small PSD

Figures 10-12 show test points 1.07 thru 1.09, respectively, which are the lower Mach $(M=0.25)$ and small PSD cases. These figures highlight the changes in ice accretion behavior as $T w b_{0}$ is reduced. Figure 10 shows the highest $T w b_{0}\left(\sim 3.0^{\circ} \mathrm{C}\right)$ case which resulted in the highest melt ratio $(\eta=23 \pm 8 \%)$ for this series of tests and produced an ice accretion that rapidly built and shed. Figures 10A-B show the ice shape just prior to the first shed. For these cases, the mid-span leading edge ice growth is shown in Fig. 10C rather than the 2D shape due to the shedding. Here, $m$ is the growth rate of ice. The initial growth rate was at a notably slower $(m \cong 0.16 \mathrm{~mm} / \mathrm{s})$ compared to subsequent build and shed events ( $m$ between 0.31 and $0.38 \mathrm{~mm} / \mathrm{s}$ ).

Figure 11 shows test point 1.08 where the $T w b_{0}$ was dropped to $\sim 0^{\circ} \mathrm{C}$ which reduced the melt ratio $(\eta=13 \pm 5 \%)$. This case resulted in an ice accretion which resembled an arrowhead shape (Fig. 11A), did not shed, and grew to over $30 \mathrm{~mm}$ at the leading edge in about 240 seconds $(m=0.124 \mathrm{~mm} / \mathrm{s})$. Figure $11 \mathrm{~B}$ shows that the ice accretion was generally uniform at the leading edge across the span. However, some non-uniformity can be seen away from the leading edge as denoted in Fig. 11B. Finally, Figure 11C shows the 2D accretion profiles presented as ice thickness versus unwrap distance from the leading edge for 3 different times after cloud activation. Here, some of the asymmetry between each side of the airfoil away from the leading edge could be attributed to some spanwise variation.

The shadow region at the bottom of Fig. 10C represents the minimum ice thickness limit which can be measured. This limit region is comprised of a perspective viewing limitation (a blind spot) and a discrimination limitation (cannot discern ice from airfoil). As previously discussed in the Image Analysis Section (Section V.F), the perspective effect creates blind spots near the airfoil surface. In this analysis, the perspective effect creates a larger blind spot region farther away from the unwrapped center. The peak shadow region near the center is a result of the imaging camera not being perfectly perpendicular to the airfoil leading edge. During these tests, the camera view was slightly in front and angled towards the airfoil to be able to image down the leading edge of the airfoil. As the initial ice accreted, the ability to discern ice from the airfoil at the leading edge was difficult, creating this discrimination limitation. Ice thickness measurements were only possible when ice grew beyond this limit near the leading edge.

Figure 12 shows test point 1.09 which was the lowest $T w b_{0}$ in this series. For this test, the $T w b_{0, T}$ was $-5^{\circ} \mathrm{C}$ although only about $-3^{\circ} \mathrm{C}$ was achieved due to a facility limitation which prevented further dry out of the air. At this $T w b_{0}$, the lowest melt ratio occurred $(\eta=8 \pm 3 \%)$. For this case, Figures 12A-B show the ice accretions at 60 seconds after cloud initiation. Shortly after this time, the side profile camera view became obscured. Also, a closer inspection of Fig. 12B shows that the maximum ice thickness occurred away from mid-span. Consequently, a 2D ice shape analysis was not performed. Rather, Figure $12 \mathrm{C}$ shows the mid-span leading edge ice growth which grew only to a thickness of about $6 \mathrm{~mm}$ after 210 seconds $(m=0.022 \mathrm{~mm} / \mathrm{s})$. 
The results from this series of test $(\mathrm{Mach}=0.25$, Small $P S D$ ) show that the leading edge ice growth rate reduced continually with $T w b_{0}$ (and consequently melt ratio). A $T w b_{0}$ of $3^{\circ} \mathrm{C}(\eta=23 \pm 8 \%)$ produced the fastest growth rate $\left(m \cong 0.35 \mathrm{~mm} / \mathrm{s}^{*}\right)$ but the accretions were not well adhered and rapidly shed. When $T w b_{0}$ was reduced to $0^{\circ} \mathrm{C}$ $(\eta=13 \pm 5 \%)$, the accretion rate decreased $(m=0.124 \mathrm{~mm} / \mathrm{s})$ but the accretion did not shed and grew to a large size. When $T w b_{0}$ was further reduced to $-3^{\circ} \mathrm{C}(\eta=8 \pm 3 \%)$, the growth rate reduced substantially $(m=0.022 \mathrm{~mm} / \mathrm{s})$ and grew to a small size with no shedding.

3. Mach $=0.4$, Large PSD

Test points $2.00-2.03(M=0.4$ and large $P S D s)$ did not produce any appreciable ice accretions and no images and figures are included from these tests. The largest growth was a trace of ice ( 2-3 mm of thickness) at the leading edge. For test point $2.00\left(T w b_{0}=6^{\circ} \mathrm{C}\right)$ and $2.01\left(T w b_{0}=3^{\circ} \mathrm{C}\right)$, the small growth occurred in the first 50 seconds while for test point $2.02\left(T w b_{0}=0^{\circ} \mathrm{C}\right)$ the ice was continually growing but only achieved $3 \mathrm{~mm}$ in 300 seconds. For these tests, there was less melting that occurred compared with the lower Mach cases at the same $T w b_{0}$ - the largest melt ratio, $\eta=14 \pm 4 \%$, occurred at a $T w b_{0}=6^{\circ} \mathrm{C}$. At $T w b_{0}=3^{\circ} \mathrm{C}$ and $0^{\circ} \mathrm{C}$, the melt ratio was $6 \pm 2 \%$ and $2 \pm 1 \%$, respectively. The large particles had a shorter residence time to melt at this faster Mach number.

\section{Mach $=0.4$, Small PSD}

Figures 13-16 show test points $2.05-2.09$, respectively, which are the higher Mach $(M=0.4)$ and small PSD cases. At the highest tested $T w b_{0}$ of $6^{\circ} \mathrm{C}$ (test point 2.05), there was significant melt $(\eta=26 \pm 9 \%$ ) resulting in a small ice shape which continually built and shed (Fig. 13). The sheds were asymmetric (i.e. only a portion of the ice along the span shed) so analysis was performed only up through the first build and shed cycle (Fig. 13C). In this case, the midspan growth was small $(m=0.073 \mathrm{~mm} / \mathrm{s})$. During this entire test sequence, the backlight was inadvertently shifted and could not be immediately corrected resulting is a bright spot obscuring the lower portion of the image. However, the light source did not affect the midspan ice-thickness measurement.

Figure 14 (test point 2.06) shows the case when $T w b_{0}$ was reduced to $3^{\circ} \mathrm{C}$. Here, the melt ratio decreased $(\eta=14 \pm 5 \%)$ and several ice build and shed cycles occurred. The analysis (Fig. 14C) shows the ice shape just before the initial shed at 19 seconds and then the initial and final profiles during the $3^{\text {rd }}$ build and shed cycle which occurred between 151-211 seconds after cloud initiation. During this $3^{\text {rd }}$ build-and-shed cycle, the resulting midspan ice thickness approached $20 \mathrm{~mm}$ at a substantial growth rate $(m=0.282 \mathrm{~mm} / \mathrm{s})$. The small peak in the shadow region at an unwrapped distance of $-6 \mathrm{~mm}$ is a mathematical anomaly that occurred in analyzing the ice thickness.

Figure 15 (test point 2.07) shows the case when $T w b_{0}=0^{\circ} \mathrm{C}$ where the melt ratio was further reduced $(\eta=7 \pm 2 \%)$. Here, the resulting ice thickness grew to about $10 \mathrm{~mm}$ at midspan after 117 seconds without shedding with several profiles shown in Fig. 15C. Unfortunately, the span view camera window became obscured after 75 seconds and the 2D profile view window became obscured after 117 seconds preventing further analysis. Figures $15 \mathrm{~A} \& \mathrm{~B}$ show the ice profile just prior to the span view camera from becoming obscured at 75 seconds. Between 18 and 67 seconds, the midspan growth rate was $m=0.051 \mathrm{~mm} / \mathrm{s}$.

Figure 16 shows test point 2.08 which attempted to reduce the humidity further compared to the previous test point. However, the facility could only achieve a $T w b_{0}=-0.4^{\circ} \mathrm{C}$ due to limitations on the flow system dehumidifiers resulting in essentially a repeat of test point 2.07 . The resulting ice accretion had a similar accretion and growth rate $(m=0.053 \mathrm{~mm} / \mathrm{s})$ to test point 2.07 as the test conditions and melt ratio $(\eta=8 \pm 3 \%)$ were nearly identical. In this case, the span view camera window became obscured after 83 seconds but the 2D profile view window remained generally unobscured - the resulting ice share grew to a thickness of almost $20 \mathrm{~mm}$ in about 300 seconds.

These series of test $(M=0.4$ and small $P S D)$, when compared with the Mach $=0.25$ tests using the same $P S D$, produced similar results. The peak growth rates for both Mach numbers were observed at $T w b_{0}=3^{\circ} \mathrm{C}$. At this $T w b_{0}$, the ice growths built and shed. At $T w b_{0}=0^{\circ} \mathrm{C}$, the ice growths adhered to the surface without shedding and the growth rates reduced for both Mach numbers. For $M=0.25$, the growth rate reduced from $0.35 \mathrm{~mm} / \mathrm{s}$ to $0.124 \mathrm{~mm} / \mathrm{s}$. For $M=0.4$, the growth rate reduced from $0.28 \mathrm{~mm} / \mathrm{s}$ to $\sim 0.06 \mathrm{~mm} / \mathrm{s}$. The data also indicated that the growth rate reduced with increasing Mach number. A final observation was that the growth rate also decreased to $m=0.073 \mathrm{~mm} / \mathrm{s}$ at the higher $T w b_{0}$ of $6^{\circ} \mathrm{C}$ for $M=0.4$ although this condition was not tested for $M=0.25$ due to time constraints.

${ }^{*}$ This is average growth rate value of the last 5 build and shed cycles seen in Fig. 10C. 


\section{B. Investigate Steady-State Ice Shapes}

Unfortunately, we were not able to get good accretion data under conditions where Currie previously ${ }^{5,12}$ observed steady-state ice accretions. These conditions were the $M=0.25$ and large $P S D$ cases (test points $1.00-1.02$ ) reported in the previous section. In these cases, the ice accretion shifted shortly after forming, possibly due to small flow misalignment or non-axisymmetric ice cloud distribution, and the resulting ice grew asymmetrically (Fig. 9).

Examination of the other cases during this test, only the $M=0.4$ and large PSD cases (test point 2.00-2.03) produced accretions that were steady-state in shape. However, these were only very small accretions of about 2-3 mm in thickness. The smaller $P S D$ cases for both $M=0.25$ and $M=0.4$ produced ice shapes which continually grew in size although the warmer $T w b_{0}$ cases did build and shed.

\section{Variation of TWC}

To investigate a possible $T W C$ threshold in ice accretion, the smaller $P S D$ and $M=0.4$ condition was selected for the $T W C$ variation as this produced the best accretion results during the first two days of testing. The other conditions were the same as during the previous tests $\left(T_{0}=15^{\circ} \mathrm{C}, P_{0}=5 \mathrm{psia}\right)$. A $T w b_{0}=0^{\circ} \mathrm{C}$ was selected for the $T W C$ variation test. The primary reason was that the $T w b_{0}=0^{\circ} \mathrm{C}$ case produced a continually increasing accretion at a $T W C=8 \mathrm{~g} / \mathrm{m}^{3}$. By reducing the $T W C$ at this $T w b_{0}$, we investigated whether we would could transition from a freezing dominated to melting dominated regime. Recall that the theory being tested indicates that a reduction of $T W C$ allows the available heat to melt more of the incoming ice thereby increasing the melting at the surface. The next higher $T w b_{0}\left(3^{\circ} \mathrm{C}\right)$ case produced a build-and-shed ice accretion at a $T W C=8 \mathrm{~g} / \mathrm{m}^{3}$ and a higher $T W C$ would be required to transition from the melting dominated to freezing dominated condition.

Two types of tests were performed to investigate the effect of increasing $T W C$ on the accretion. The first type was a TWC sweep where the ice feed rate was increased in increments during the same spray. This test was intended to quickly identify a possible threshold from the melting to freezing dominated regime. For these tests, the TWC was not able to be measured during the test (since inserting the probes would contaminate the ice shape) but would later be estimated based on calibrations from subsequent tests. Figure 17 shows images of the ice accretion from near the end of this test (Test Point 3.01). The second type of test maintained a given TWC (i.e. constant ice feed rate) during a given spray (Test Points 3.02, 3.03, 3.11). For these latter tests, the $T W C$ was increased in subsequent sprays and the airfoil was deiced between tests. An advantage of these latter types of tests was that the $T W C$ and melt ratio could be directly measured. Figures $18-20$ show images of the ice accretion from these tests.

Figure 21A shows the leading edge ice thickness at midspan as a function of time during the TWC sweep (Test Point 3.01). The $T W C$ values are estimated using the data from Test Points 3.02, 3.03, and 3.11 and assuming a linear relationship between the ice feed rate and TWC. This figure shows only a small accretion occurred at TWC $=2$ and $3 \mathrm{~g} / \mathrm{m}^{3}$ but began to grow more significantly at $4 \mathrm{~g} / \mathrm{m}^{3}$ and higher. It should be noted that this increase in growth rate was not easily discernable from the video directly without analysis.

Figure 21B shows the leading edge ice thickness at midspan as a function of time Test Points 3.02, 3.03, and 3.11 where the $T W C$ was maintained constant at values of 3,6 , and $10 \mathrm{~g} / \mathrm{m}^{3}$, respectively. Also included in this figure is the data from the early portion of test point 3.01 when the $T W C$ was $2 \mathrm{~g} / \mathrm{m}^{3}$ and test points 2.07 which had a $T W C=8$ $\mathrm{g} / \mathrm{m}^{3}$ but otherwise identical aero-thermal and $P S D$ conditions.

Except for an initial transient, the growth rates were roughly linear with time for both the $T W C$ sweep and discrete TWC runs. For the TWC sweep (test point 3.01), the growth rates were extracted from linear curve fits of the data during the portions of time when the $T W C$ was held constant. The linear fits can be seen as green lines in Fig. 21A with the slopes shown in the text boxes. Figure 21B also shows the linear curve fits and slopes for the discrete TWC runs. In these cases, the initial transient was avoided by beginning the curve fit after $\sim 30$ seconds of accretion. Test point $3.02\left(T W C=3 \mathrm{~g} / \mathrm{m}^{3}\right)$ was analyzed using the automated routine due to no window obscuration hence the significantly larger number of data points compared to the other test points.

Figure $21 \mathrm{C}$ show a bar chart comparing the ice growth rates versus $T W C$ bin for the various cases above including the $T W C$ sweep and discrete $T W C$ cases. In general, the ice growth rate increased with $T W C$. For a $T W C$ of $3 \mathrm{~g} / \mathrm{m}^{3}$, both the $T W C$ sweep and discrete $T W C$ case produced an almost identical growth. At $6 \mathrm{~g} / \mathrm{m}^{3}$, the discrete $T W C$ test (Test Point 3.03) produced a growth rate that was 50\% greater than what was measured during the TWC sweep (Test Point 3.01). It is not clear why these two growth rates were so different between the two difference types of tests. A notable difference between the two tests showed that the $T W C$ sweep became more asymmetric during the very long spray. This can be seen by the images of the ice growth shown in Fig. 17. Also, Test Point 3.03 could only be analyzed 
for the first 160 seconds due to window obscuration. Admittedly, it is not clear if the two growth rates should be the same given the different starting initial conditions at the surface between these two tests (i.e. clean vs. iced airfoil).

The legend of Fig. 21B includes the melt ratio measurements for the discrete $T W C$ cases. The melt ratio increased slightly with $T W C$ although the uncertainty estimates of the melt ratio measurement prevent this from being a definitive conclusion. One possible explanation is that the $T w b_{0}$ increased slightly with TWC (see measurements in the Table Section), resulting in more melt. If this melt ratio trend is correct then it complicates the interpretation of the effect of $T W C$ since both melt ratio and $T W C$ were varying. Furthermore, a more general conclusion regarding melt ratio is that if variations of a few percent in melt ratio need to be discerned then more work needs to be done to reduce the uncertainty of the measurement either through improvements in existing instrumentation or development of new instrumentation.

The results of the $T W C$ variation tests do suggest a threshold below which accretion would not occur for these test conditions. The threshold was approached as $T W C$ was reduced although the growth rate never went to exactly zero. However, the growth rates at 2 and $3 \mathrm{~g} / \mathrm{m}^{3}$ were barely perceptible producing only up to a few millimeters of ice in 4 minutes of cloud exposure. Incidentally, a $T W C$ of $\sim 2 \mathrm{~g} / \mathrm{m}^{3}$ approached the lowest ice feedrate limit for the RATFac. Finally, it is difficult to determine from the experimental observations whether the surface energy balance transitioned from a freezing to melting dominated regime - to do so will require analysis similar to that described by Bartkus et al. ${ }^{30}$

\section{Discussion}

The overarching objective of this test was to provide data to the icing community on ice crystal ice accretion and the conditions leading to those accretions. As such, the overall objective was achieved and further insight into the accretion process can be gained by comparing these results to accretion models. The factors affecting ice accretion examined in the current testing included wet-bulb temperature, total water content, melt ratio, Mach number, and particle size distribution. With the current experimental setup, it is difficult to independently vary any one of these factor as they are all coupled. For example, there is only one melt ratio that occurs through natural melt for a given wet-bulb temperature, total water content, Mach number, and particle size distribution. Supplemental water tests could be used to enhance the melt fraction but the thermal state and particle size distribution of the supplemental water then needs separate characterization and could be significantly different than the naturally melted cloud. Nonetheless, the natural melting of ice-crystals is the process that occurs within the jet engine and the coupling of icing parameters occurs within that environment making the present experiments a good analog for understanding the associated physics of ice-crystal icing.

\section{Conclusions}

This paper presented results from a study of the fundamental physics of ice-crystal ice accretion using a NACA 0012 airfoil at the NRC RATFac which took place during August 2017. These tests were part of a collaborative effort between NASA and NRC which began in 2010. The overarching objective of this test was to generate ice accretions for the purpose of developing and validating ice-crystal icing codes. More specific objectives included (A) examining accretions under different wet-bulb temperatures, (B) investigations of steady-state ice shapes previously reported in the literature, (C) total water content variations in search of a threshold for accretion, and (D) probe characterization with the objective of measuring melt ratio. Two particle size distributions were used during this test program, a small $\left(D v_{50} \sim 28 \mu \mathrm{m}\right)$ and large $\left(D v_{50} \sim 50 \mu \mathrm{m}\right) P S D$. The particle sizes were measured for each test and are reported in the paper.

For the wet-bulb temperature variation tests, good accretion data was obtained using the small PSD cloud at two tested Mach numbers of 0.25 and 0.4. In general, all the ice shapes observed in this test had sharp arrow-like accretions characteristic of erosion caused by ice crystals. At both Mach numbers, two general types of icing behavior were observed: building and shedding ice at warmer wet-bulb temperature $\left(T w b_{0}>=3^{\circ} \mathrm{C}\right)$, and adhered ice at wet bulb temperature nearer freezing. In general, the ice growth rates decreased at higher Mach number at a given wet-bulb temperature. For Mach $=0.4$ and small PSD cases, the ice growth rate increased then decreased with melt ratio.

Due to a small flow misalignment or slight cloud non-uniformity which resulted in an asymmetric ice shape, good accretion data was not obtained under conditions where Currie previously ${ }^{5,12}$ observed steady-state ice accretions 
( $M=0.25$ and large $P S D$ cases). No ice accretion occurred for the M=0.4 and large PSD cases presumably due to the smaller melt ratios achieved in these tests.

Tests varying the $T W C$ at $T w b_{0}=0^{\circ} \mathrm{C}$ resulted in increasing ice growth rates with $T W C$ although at $3 \mathrm{~g} / \mathrm{m}^{3}$ and lower, the growths rates were very small $(\sim 0.5 \mathrm{~mm} / \mathrm{min}$ or lower). The largest growth rates observed were $\sim 6 \mathrm{~mm} / \mathrm{min}$ at $10 \mathrm{~g} / \mathrm{m}^{3}$. During the $T W C$ variation tests, the melt fraction decreased slightly with $T W C$ making it difficult to isolate the effects of $T W C$ separately from melt ratio.

Finally, this paper presented data on estimating the melt ratio using the SEA Multi-Element probe and an Isokinetic TWC Probe. The data included additional characterization of the SEA Multi-Element false response signal due to ice crystals which needs to be accounted for when using liquid water sensors of the probe. An uncertainty analysis was performed on the current data set which showed that the melt ratio uncertainty was $25 \%$ or greater (increasing with lower melt). Thus, further work is recommended to improve the accuracy of melt ratio measurements.

\section{Acknowledgment}

The authors wish to acknowledge the financial support for this work by the Advanced Aircraft Icing (AAI) Subproject of the NASA Advanced Air Transport Technology Project (AATT) under NASA's, Advanced Air Vehicle's program and the National Research Council of Canada's program in Reducing Aviation Icing Risk (RAIR). The authors would also like to thank Sean Sharyari Fard for his excellent work on analyzing the NRC PIV image data.

\section{References}

${ }^{1}$ Struk, P., Currie, T., Wright, W. B., Knezevici, D. C., Fuleki, D., Broeren, A., Vargas, M., and Tsao, J. "Fundamental Ice Crystal Accretion Physics Studies," SAE 2011 International Conference on Aircraft and Engine Icing and Ground Deicing, SAE Technical Paper 2011-38-0018 or NASA/TM-2012-217429, 2011.

${ }^{2}$ Knezevici, D. C., Fuleki, D., and MacLeod, J. "Development and Commissioning of the Linear Compressor Cascade Rig for Ice Crystal Research," SAE 2011 International Conference on Aircraft and Engine Icing and Ground Deicing SAE Technical Paper 2011-38-0079, 2011.

${ }^{3}$ Currie, T. C., Struk, P. M., Tsao, J., Fuleki, D., and Knezevici, D. C. "Fundamental Study of Mixed-Phase Icing with Application to Ice Crystal Accretion in Aircraft Jet Engines," 4th Atmospheric and Space Environments Conference, AIAA 2012-3035, 2012.

${ }^{4}$ Mason, J. G., Strapp, J. W., and Chow, P. "The Ice Particle Threat to Engines in Flight," 44th AIAA Aerospace Sciences Meeting and Exhibit, AIAA-2006-206, Reno, NV, 2006.

${ }^{5}$ Currie, T. C., Fuleki, D., and Mahallati, A. "Experimental Studies of Mixed-Phase Sticking Efficiency for Ice Crystal Accretion in Jet Engines," 6th AIAA Atmospheric and Space Environments Conference, AIAA-2014-3049, Atlanta, GA, 2014.

${ }^{6}$ Davison, C. R., Benner, M., Landreville, C., and Fuleki, D. "Development and Validation of Compact Isokinetic Total Water Content Probe for Wind Tunnel Characterization," 8th AIAA Atmospheric and Space Environments Conference, AIAA-2016-4052, 2016.

${ }^{7}$ Struk, P. M., Bencic, T., Tsao, J., Fuleki, D., and Knezevici, D. C. "Preparation for Scaling Studies of Ice-Crystal Icing at the NRC Research Altitude Test Facility," 5th AIAA Atmospheric and Space Environments Conference, AIAA-2013-2675 and NASA/TM-2013-216571, 2013.

${ }^{8}$ Fuleki, D., Mahallati, A., Currie, T. C., MaCleod, J. D., and Knezevici, D. C. "Development of a Sensor for Total Temperature and Humidity Measurements under Mixed-Phase and Glaciated Icing Conditions," 6th AIAA Atmospheric and Space Environments Conference, 2014.

${ }^{9}$ Bartkus, T. P., Struk, P. M., and Tsao, J.-C. "Comparisons of Mixed-Phase Icing Cloud Simulations with Experiments Conducted at the NASA Propulsion Systems Laboratory," 9th AIAA Atmospheric and Space Environments Conference. American Institute of Aeronautics and Astronautics, Denver, CO, 2017.

${ }^{10}$ Bartkus, T. P., Struk, P. M., Tsao, J. C., and Van Zante, J. F. "Numerical Analysis of Mixed-Phase Icing Cloud Simulations in the NASA Propulsion Systems Laboratory," 8th AIAA Atmospheric and Space Environments Conference, AIAA-2016-3739, 2016.

${ }^{11}$ Bartkus, T. P., Struk, P. M., and Tsao, J. C. "Development of a Coupled Air and Particle Thermal Model for Engine Icing Test Facilities," SAE Int. J. Aerosp. Vol. 8, No. 1, 2015. p. 18.

${ }^{12}$ Currie, T. C., Fuleki, D., Knezevici, D. C., and MacLeod, J. D. "Altitude Scaling of Ice Crystal Accretion," 5th AIAA Atmospheric and Space Environments Conference, AIAA-2013-2677, 2013. 
${ }^{13}$ Tsao, J., Struk, P. M., and Oliver, M. J. "Possible Mechanisms for Turbofan Engine Ice Crystal Icing at High Altitude," 6th AIAA Atmospheric and Space Environments Conference, AIAA-2014-3044, 2014.

${ }^{14}$ Knezevici, D. C., Fuleki, D., Currie, T. C., Galeote, B., Chalmers, J., and MacLeod, J. D. "Particle Size Effects on Ice Crystal Accretion - Part II," 5th AIAA Atmospheric and Space Environments Conference, AIAA-2013-2676, 2013.

${ }^{15}$ Knezevici, D. C., Fuleki, D., Currie, T. C., and MacLeod, J. D. "Particle Size Effects on Ice Crystal Accretion," 4th AIAA Atmospheric and Space Environments Conference, AIAA 2012-3039, 2012.

${ }^{16}$ Currie, T. C., and Fuleki, D. "Experimental Results for Ice Crystal Icing on Hemispherical and Double Wedge Geometries at Varying Mach Numbers and Wet Bulb Temperatures," 8th AIAA Atmospheric and Space Environments Conference, AIAA-2016-3740, 2016.

${ }^{17}$ Struk, P. M., Bartkus, T. P., Tsao, J. C., Currie, T., and Fuleki, D. "Ice Accretion Measurements on an Airfoil and Wedge in Mixed-Phase Conditions," SAE 2015 International Conference on Icing of Aircraft, Engines, and Structures, SAE Technical Paper 2015-01-2116, Prague, CZ, 2015.

${ }^{18}$ Steen, L. E., Ide, R. F., and Van Zante, J. F. "An Assessment of the Icing Blade and the SEA Multi-Element Sensor for Liquid Water Content Calibration of the NASA GRC Icing Research Tunnel," 8th AIAA Atmospheric and Space Environments Conference, AIAA-2016-4051, Washington, DC, 2016.

${ }^{19}$ Rigby, D. L., Struk, P. M., and Bidwell, C. S. "Simulation of fluid flow and collection efficiency for an SEA multi-element probe," 6th AIAA Atmospheric and Space Environments Conference, AIAA-2014-2752, Atlanta, GA, 2014.

${ }^{20}$ Lilie, L., Emery, E., Strapp, J. W., and Emery, J. "A Multiwire Hot-Wire Device for Measurment of Icing Severity, Total Water Content, Liquid Water Content, and Droplet Diameter " 43rd AIAA Aerospace Sciences Meeting and Exhibit, AIAA-2005-859, Reno, Nevada, 2005.

${ }^{21}$ Fuleki, D. M., Chalmers, J. Y., and Galeote, B. "Technique for Ice Crystal Particle Size Measurements and Results for the National Research Council of Canada Altitude Ice Crystal Test System," SAE 2015 International Conference on Icing of Aircraft, Engines, and Structures, SAE Technical Paper 2015-01-2125, 2015.

${ }^{22}$ Galeote, B. "Ice Crystal Particle Measurement Using Shadowgraph Imaging Techniques," AIAA Atmospheric and Space Environments Conference, AIAA 2010-7531, 2010.

${ }^{23}$ King, M. C., Bachalo, W., and Kurek, A. "Particle Size Measurements from the first Fundamentals of Ice Crystal Icing Physics Test in the NASA Propulsion Systems Laboratory," 9th AIAA Atmospheric and Space Environments Conference. American Institute of Aeronautics and Astronautics, 2017.

${ }^{24}$ Struk, P. M., Rigby, D. L., and Venkataraman, K. "A Thermal Analysis of a Hot-Wire Probe for Icing Applications," 6th AIAA Atmospheric and Space Environments Conference, AIAA-2014-2331, Atlanta, GA, 2014.

${ }^{25}$ Struk, P. M., Ratvasky, T. P., Bencic, T., Van Zante, J. F., King, M. C., Tsao, J.-C., and Bartkus, T. P. "An Initial Study of the Fundamentals of Ice Crystal Icing Physics in the NASA Propulsion Systems Laboratory," 9th AIAA Atmospheric and Space Environments Conference, AIAA-2017-4242, 2017.

${ }^{26}$ Moffat, R. J. "Describing the Uncertainties in Experimental Results," Experimental Thermal and Fluid Science Vol. 1, 1988. pp. 3-17.

${ }^{27}$ Avigilon Control Center Software. 2018. URL: http://avigilon.com/ [cited 2/26/2018].

${ }^{28}$ Rasband, W. S. ImageJ. 1997-2012. URL: http://imagej.nih.gov/ij/

${ }^{29}$ Wavemetrics, I. Igor Pro 7. 2017. URL: http://www.wavemetrics.com/

${ }^{30}$ Bartkus, T. P., Tsao, J. C., and Struk, P. M. "Evaluation of a Thermodynamic Ice-Crystal Icing Model Using Experimental Ice Accretion Data," 10th Atmospheric and Space Environments Conference. American Institute of Aeronautics and Astronautics, 2018 (to be published).

${ }^{31}$ Davison, C. R., Strapp, J. W., Lilie, L. E., Ratvasky, T. P., and Dumont, C. "Isokinetic TWC Evaporator Probe: Calculations and Systemic Error Analysis," 8th AIAA Atmospheric and Space Environments Conference, AIAA-20164060, 2016. 


\section{Figures}

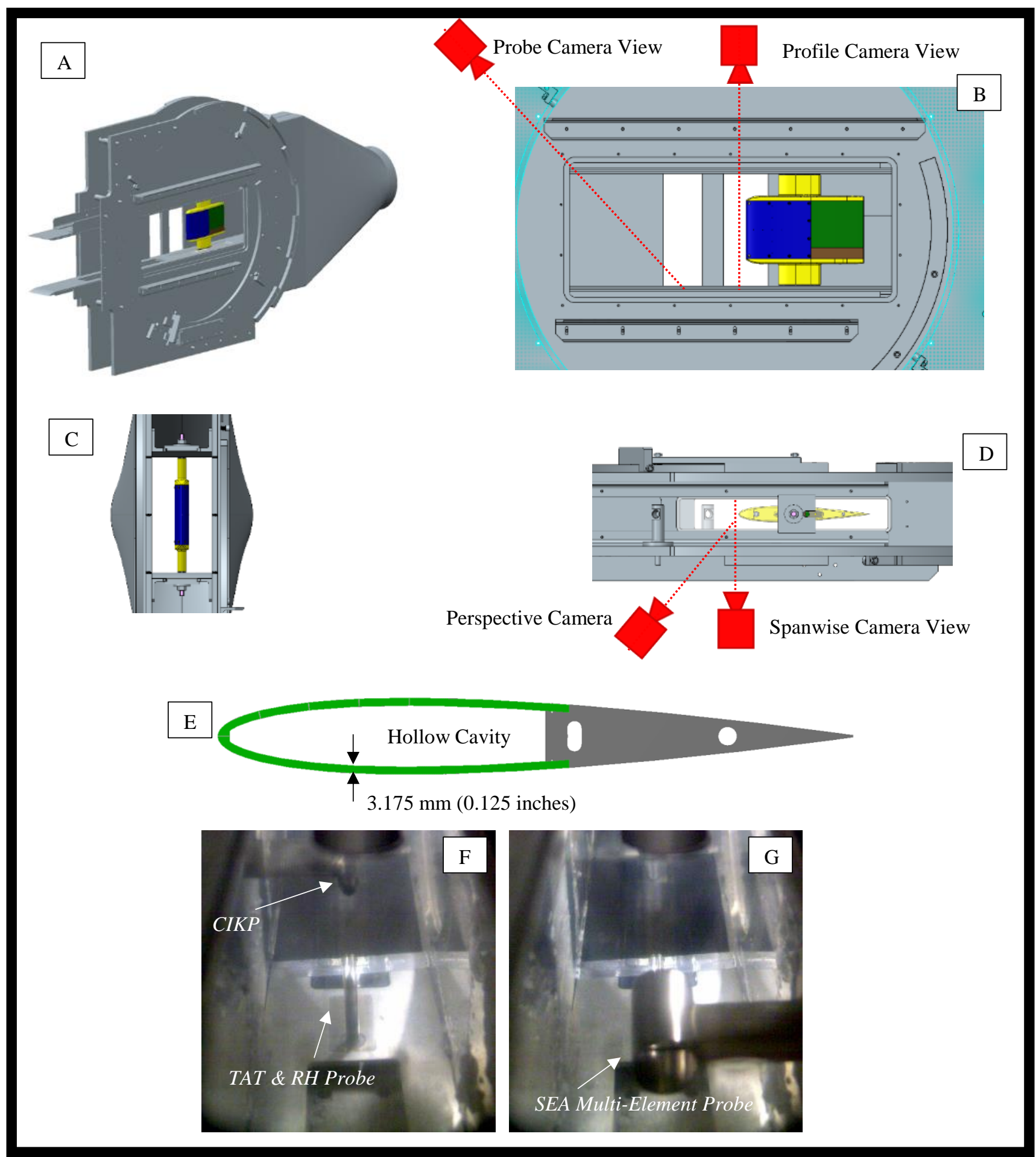

Figure 1. NACA 0012 airfoil model mounted vertically in NRC Cascade rig. Various orientations of the model and camera views are shown in images $(A)-(D)$. Image (E) shows a cut away section of the airfoil at mid span. Images (F) and (G) show the CIKP and SEA Multi-Element probes, respectively, while inserted in the flow from the probe camera view.

19

American Institute of Aeronautics and Astronautics 


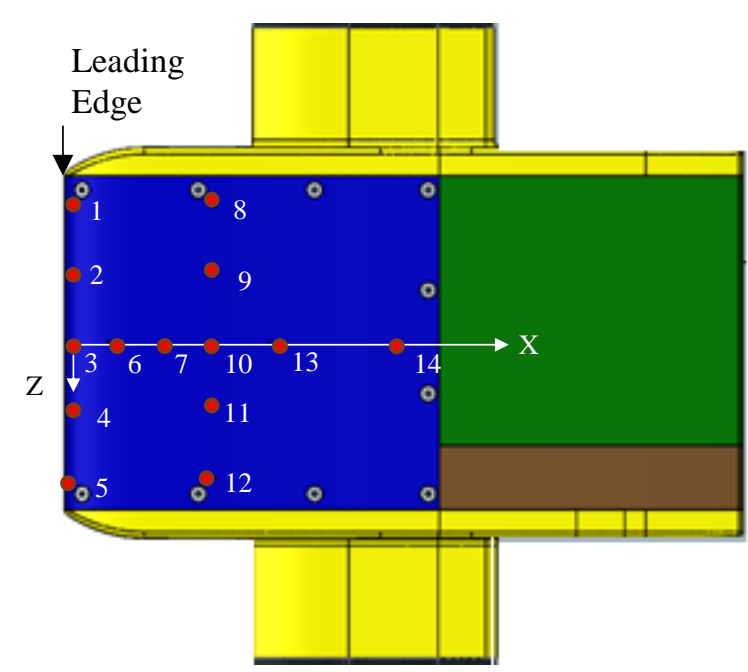

\begin{tabular}{|c|c|c|c|}
\hline TC\# & $\mathrm{X}$ & $\mathrm{Y}$ & $\mathrm{Z}$ \\
\hline 1 & 0.000 & 0.000 & -5.334 \\
\hline 2 & 0.000 & 0.000 & -2.667 \\
\hline 3 & 0.000 & 0.000 & 0.000 \\
\hline 4 & 0.000 & 0.000 & 2.667 \\
\hline 5 & 0.000 & 0.000 & 5.334 \\
\hline 6 & 1.712 & 1.052 & 0.000 \\
\hline 7 & 3.802 & 1.402 & 0.000 \\
\hline 8 & 5.918 & 1.560 & -5.334 \\
\hline 9 & 5.918 & 1.560 & -2.667 \\
\hline 10 & 5.918 & 1.560 & 0.000 \\
\hline 11 & 5.918 & 1.560 & 2.667 \\
\hline 12 & 5.918 & 1.560 & 5.334 \\
\hline 13 & 8.039 & 1.600 & 0.000 \\
\hline 14 & 13.907 & 1.374 & 0.000 \\
\hline 15 & 13.907 & 0.000 & 0.000 \\
\hline
\end{tabular}

Figure 2. Thermocouple definitions relative to the leading edge at midspan (dimension are in centimeters). The dimensions $X$ and $Z$ are shown in the figure while the dimension $Y$ is out of the page. The thermocouples not on the leading edge (\#6-\#14) are only on the side of the model as shown in the image. Thermocouple \#15 is located within the model on the metal surface at the aft end of the hollow air cavity (just under \#14 in the image).
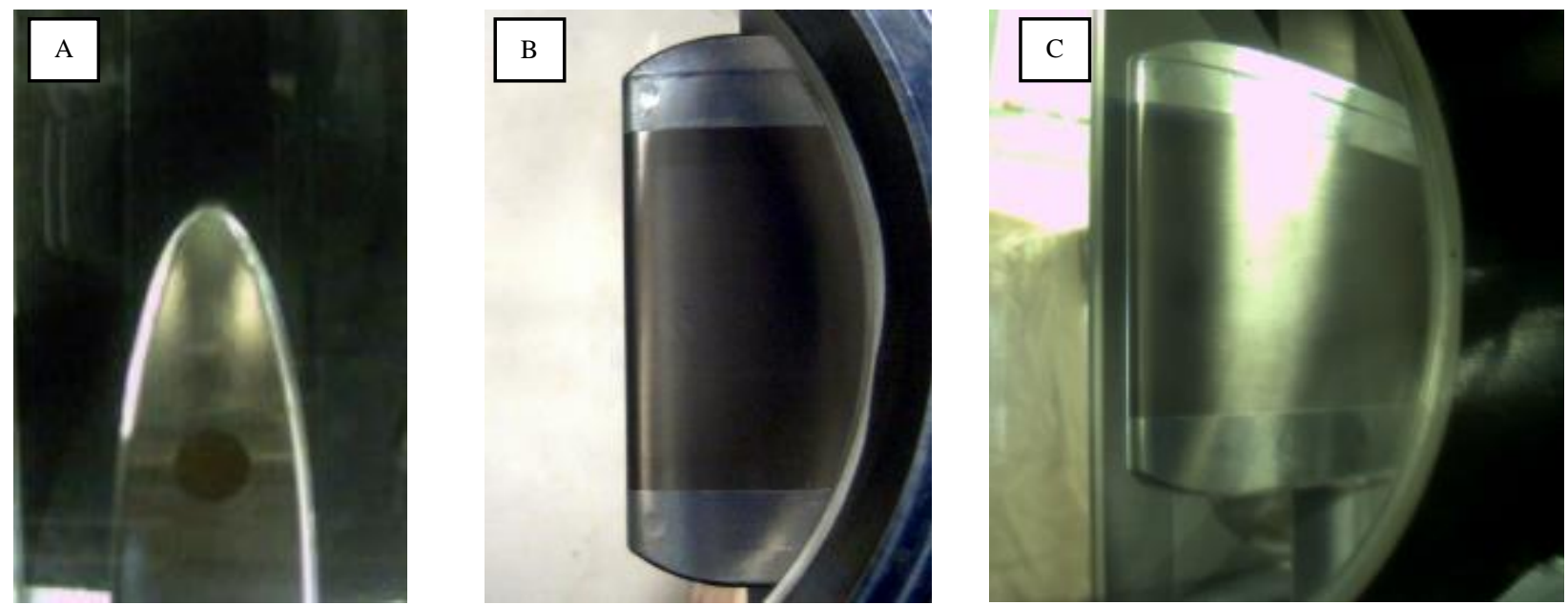

Figure 3. Video camera views of the NACA 0012 airfoil available during testing: $(A) 2 D$ view, (B) span view, and (C) perspective view. 


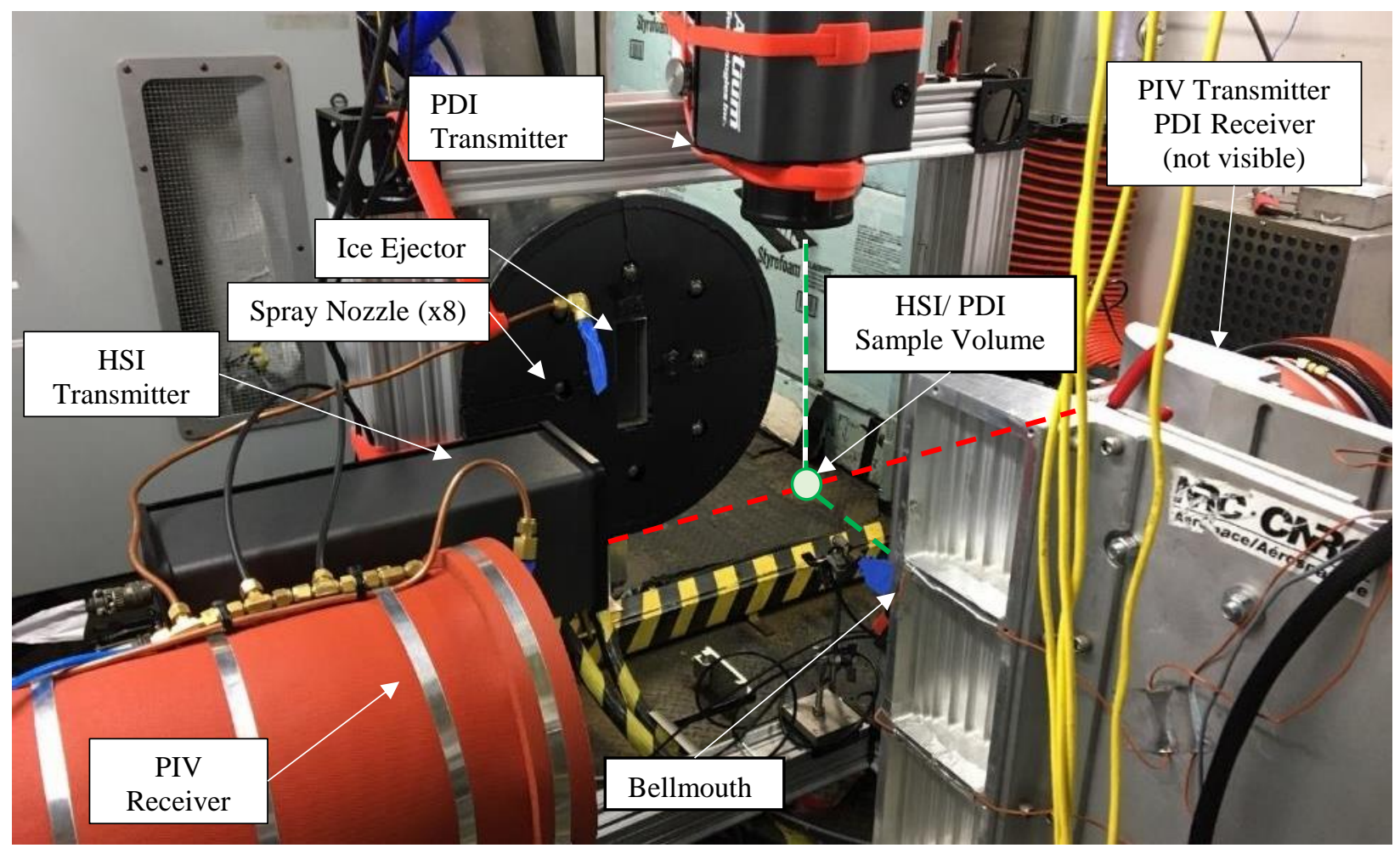

Figure 4. Particle measurement hardware setup used during this experiment. The sample volumes for the PIV and HSI/PDI systems were approximately $7 \mathrm{~cm}$ ( $2.75 \mathrm{in}$.) and $32 \mathrm{~cm}$ ( 12.5 inches), respectively, upstream of the bellmouth entrance at the tunnel centerline. The distance from the bellmouth entrance to the test section was $102.1 \mathrm{~cm}$. Note that the PIV transmitter and PDI receiver are behind the bellmouth and not visible in this image.

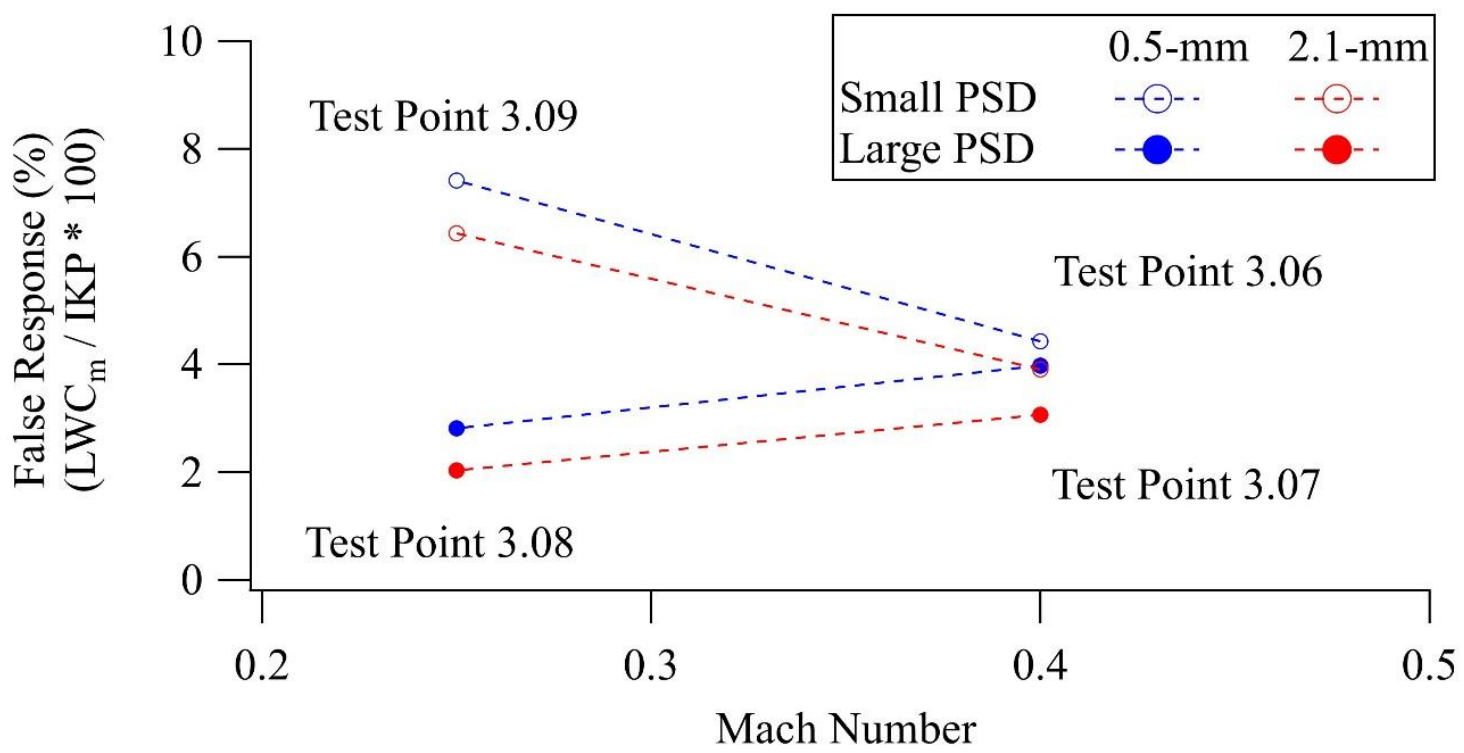

Figure 5. SEA Multi-element false response as a function of Mach number and particle size distribution. The false response is the multi-element measurement from the LWC sensors (0.5- $\mathrm{mm}$ and 2.1- $\mathrm{mm}$ ) divided by the CIKP measurement. The multielement measurements were adjusted for collision efficiency. 


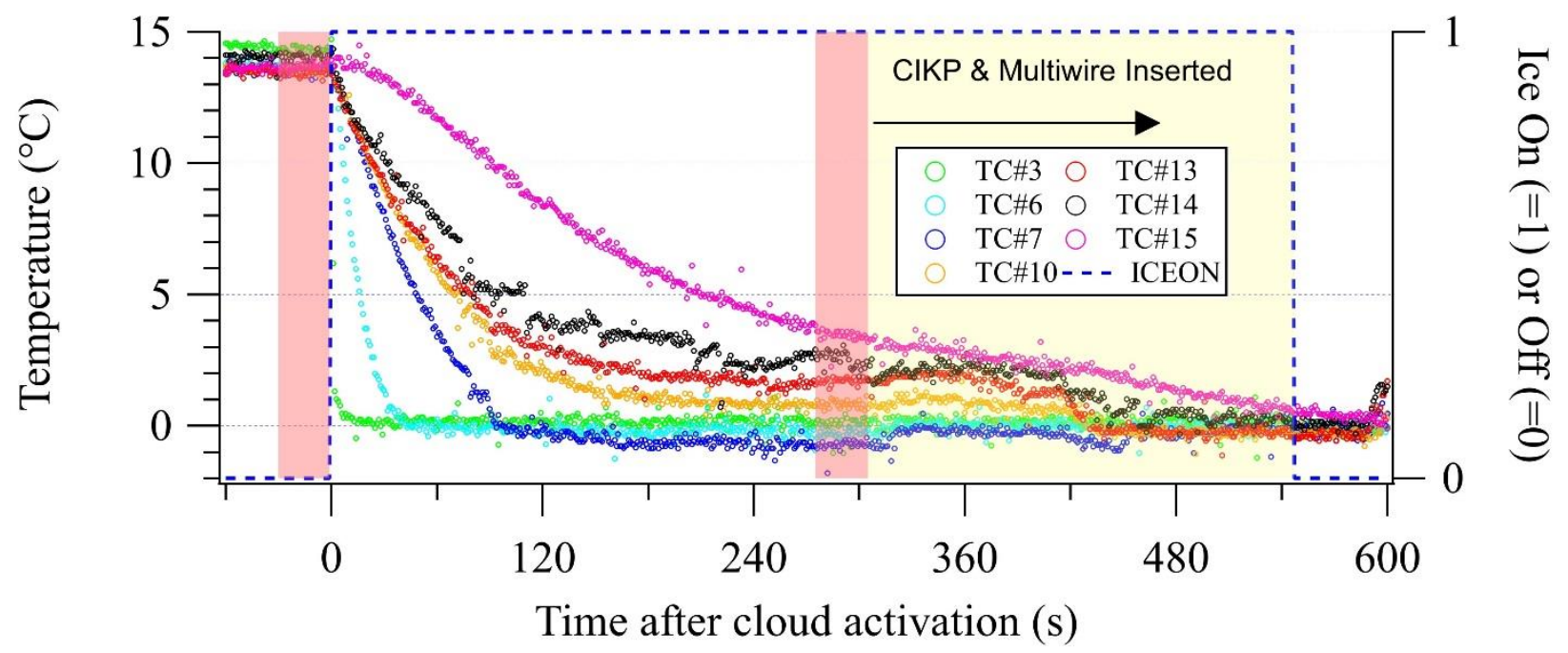

Figure 6. Midspan thermocouple measurements for Test Point 3.11. For the remainder of the test points, the initial and final 30-second averages of temperature are reported in Table 5. The averaging periods are shown in the red boxed regions (-30 to 0 seconds and 285-305 seconds in the example shown in the figure). Once the CIKP or the multiwire are inserted (at 305 seconds in this case), surface temperature measurements can be affected by the upstream probes and data after this point is not analyzed.

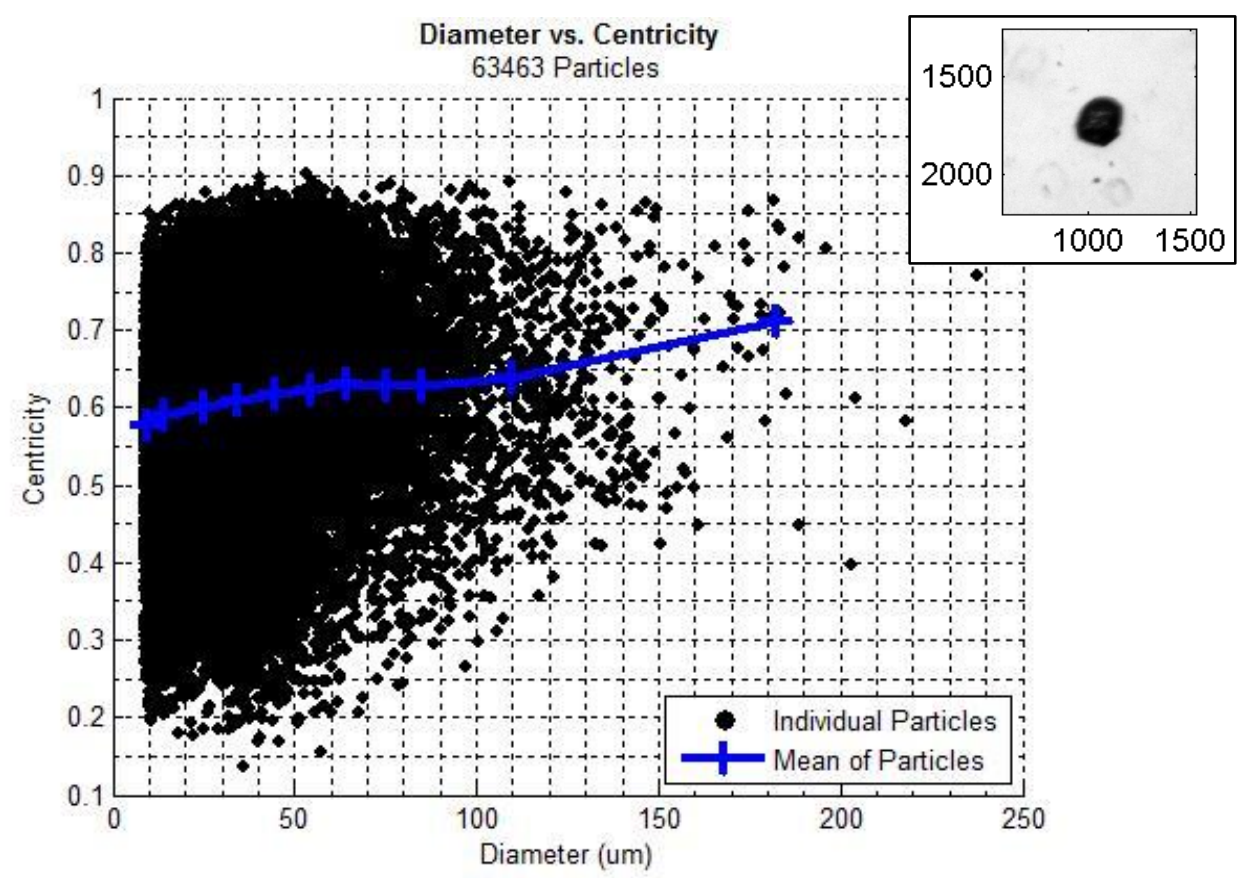

Figure 7. Centricity (Фmin/Фmax) versus diameter for TP1.04, grinder configuration A2-large. The inset shows a sample NRC PIV image of ice particle from TP1.04, $\Phi=237 \mu \mathrm{m}$. 


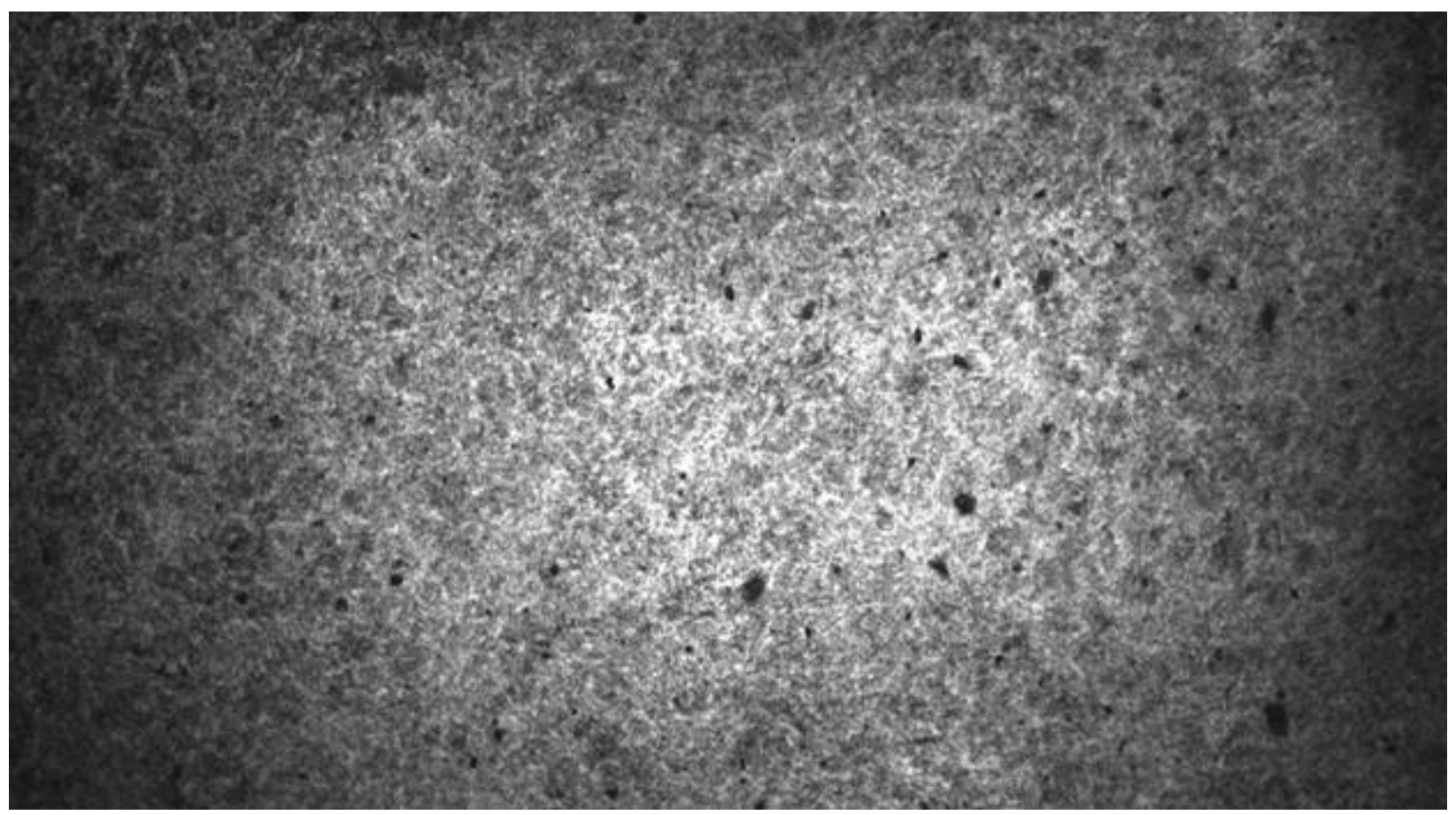

Figure 8. HSI sample image during a larger PSD spray.

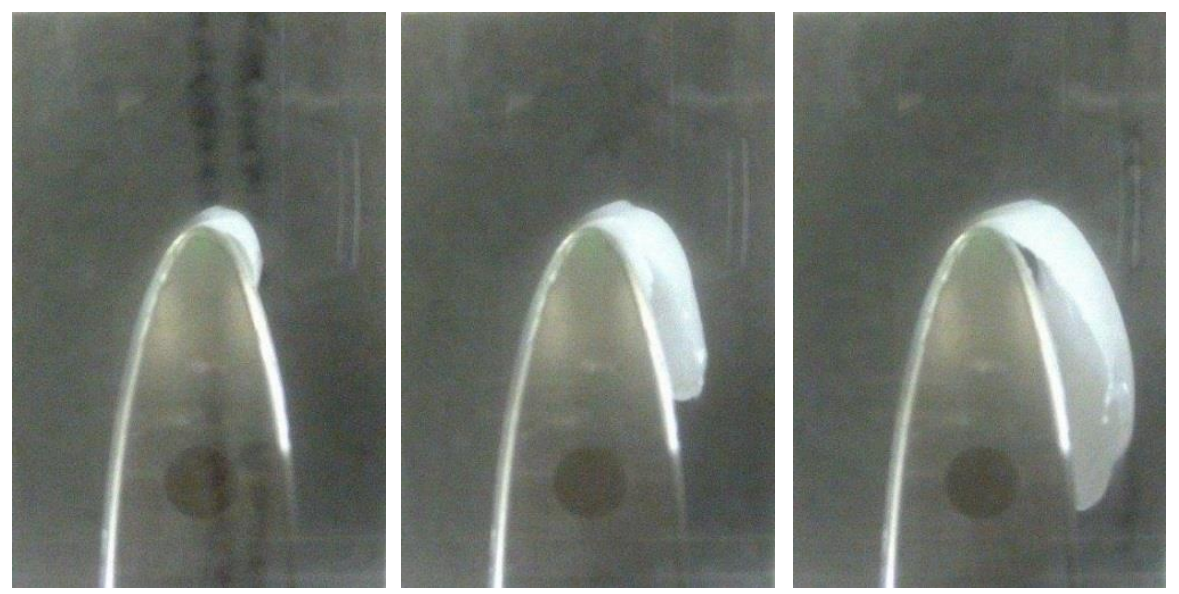

Figure 9. Asymmetric ice shape evolution observed during Test Point 1.02, Scan $917\left(M=0.25, T_{0}=15^{\circ} \mathrm{C}, P_{0}=5\right.$ psia, large PSD, $\left.T w b_{0}=6^{\circ} \mathrm{C}\right)$. This data was not analyzed.

American Institute of Aeronautics and Astronautics 

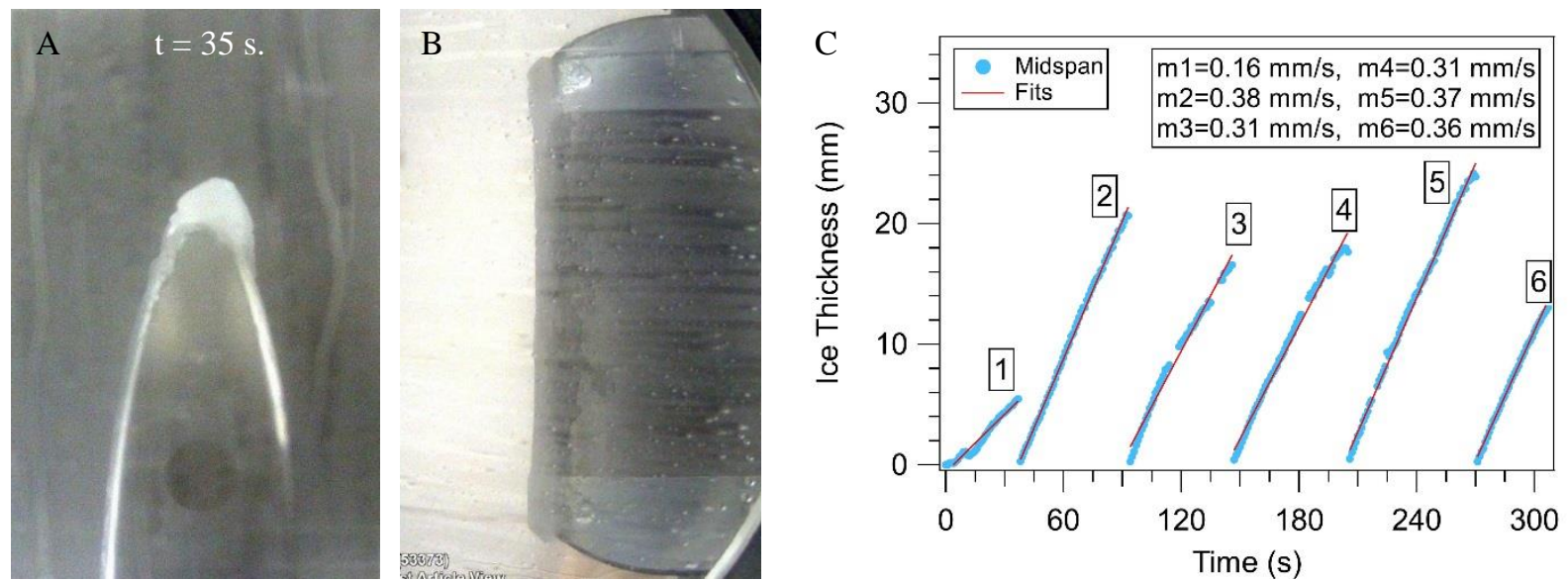

Figure 10. Ice shapes ( $A$ and $B$ ) after 35 seconds of accretion and midspan growth rate accretion analysis (C) for Test Point 1.07, Scan $974\left(M=0.25, T_{0}=15^{\circ} \mathrm{C}, P_{0}=5\right.$ psia, small $\left.P S D, T w b_{0}=3^{\circ} \mathrm{C}\right)$.
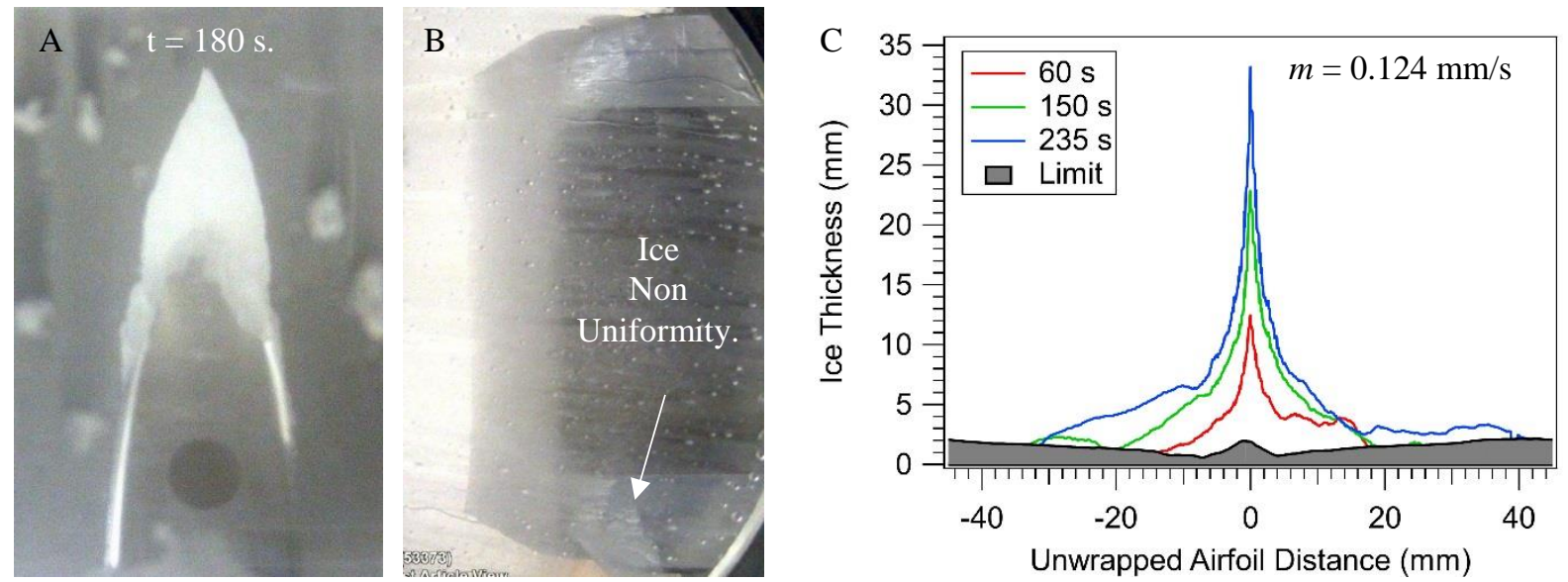

Figure 11. Final ice shapes $(A$ and $B)$ and $2 D$ profile accretion analysis for Test Point 1.08, Scan $972\left(M=0.25, T_{0}=15^{\circ} C, P_{0}=5\right.$ psia, small PSD, Twb $b_{0} 0^{\circ} \mathrm{C}$ ) after 180 seconds of accretion. The shadow region at the bottom of Fig. $10 \mathrm{C}$ represents the minimum ice thickness limit which can be measured due to camera alignment and a perspective effect causing a blind spot.
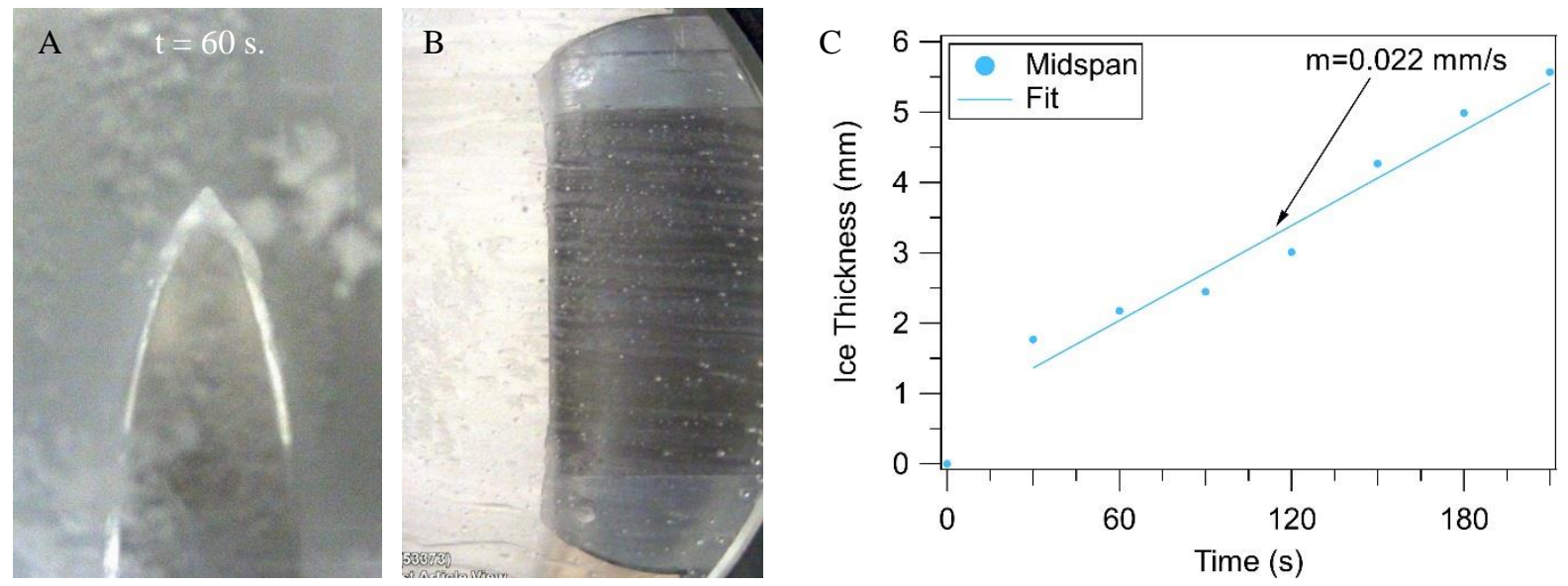

Figure 12. Final ice shapes $(A$ and $B$ ) and midspan growth rate accretion analysis (C) for Test Point 1.09, Scan 970 (M=0.25, $T_{0}=15^{\circ} \mathrm{C}, P_{0}=5$ psia, small $P S D, T w b_{0}=-3^{\circ} \mathrm{C}$ ) after 60 seconds of accretion. 

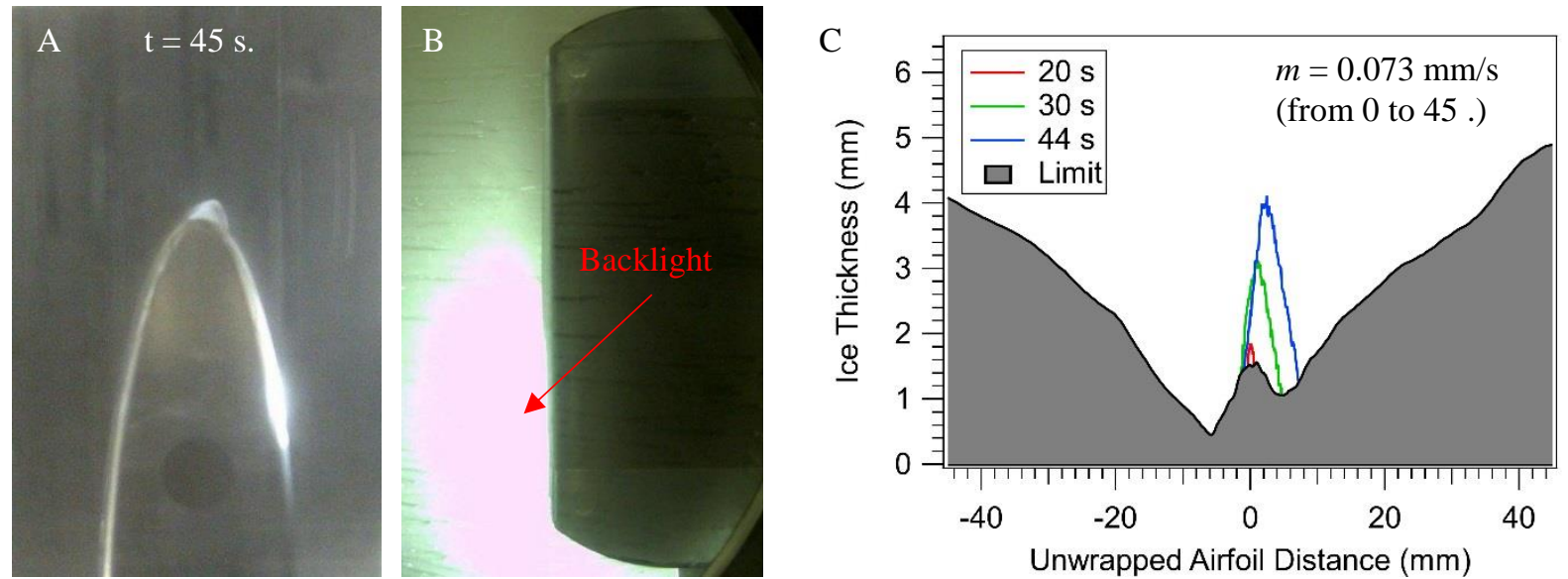

Figure 13. Ice shapes (A and $B$ ) and $2 D$ profile accretion analysis $(C)$ through the first build cycle (approximately 45 seconds of accretion time) for Test Point 2.05, Scan $938\left(M=0.4, T_{0}=15^{\circ} \mathrm{C}, P_{0}=5\right.$ psia, small $\left.P S D, T w b_{0}=6^{\circ} \mathrm{C}\right)$. During this test sequence, the backlight was inadvertently shifted resulting is a bright spot obscuring the lower portion of the image.
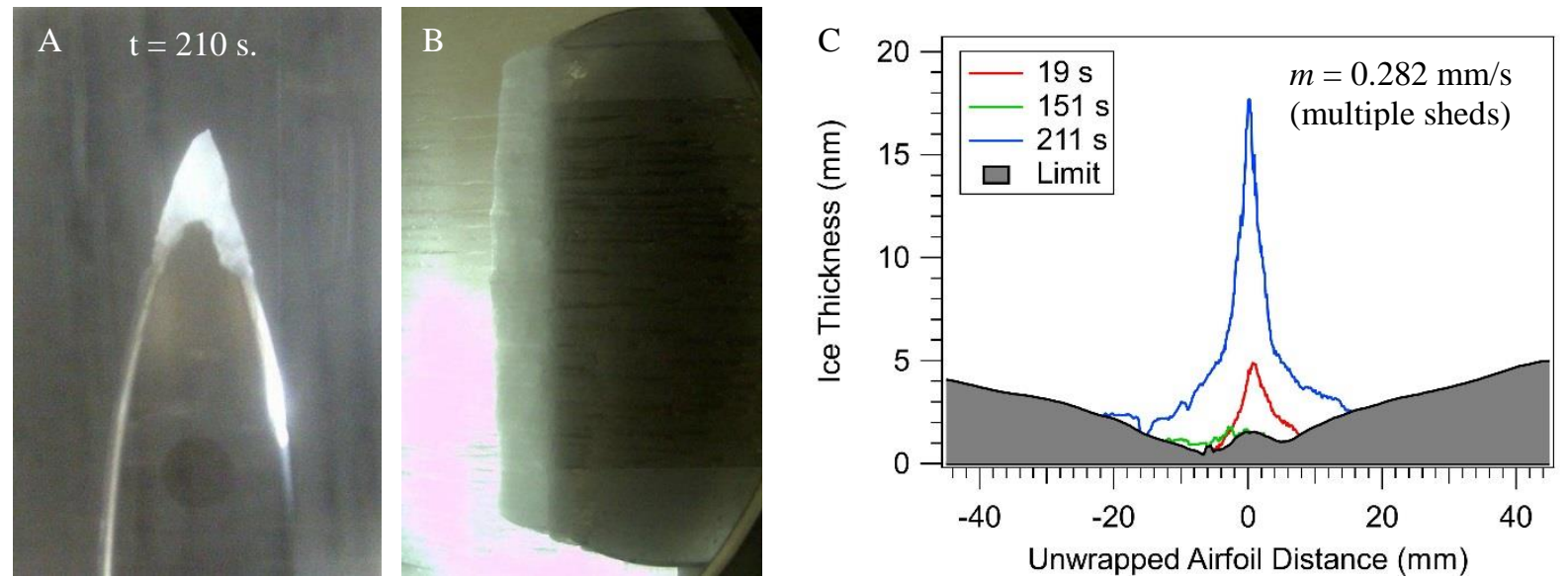

Figure 14. Ice shapes $(A$ and $B)$ and $2 D$ profile accretion analysis $(C)$ for Test Point 2.06, Scan $940\left(M=0.4, T_{0}=15^{\circ} C, P_{0}=5\right.$ psia, small PSD, $T w b_{0}=3^{\circ} \mathrm{C}$ ) after 210 seconds of accretion. The midspan growth rate was calculated from 150 to 210 seconds after a complete ice shed event at $t=150$ seconds.
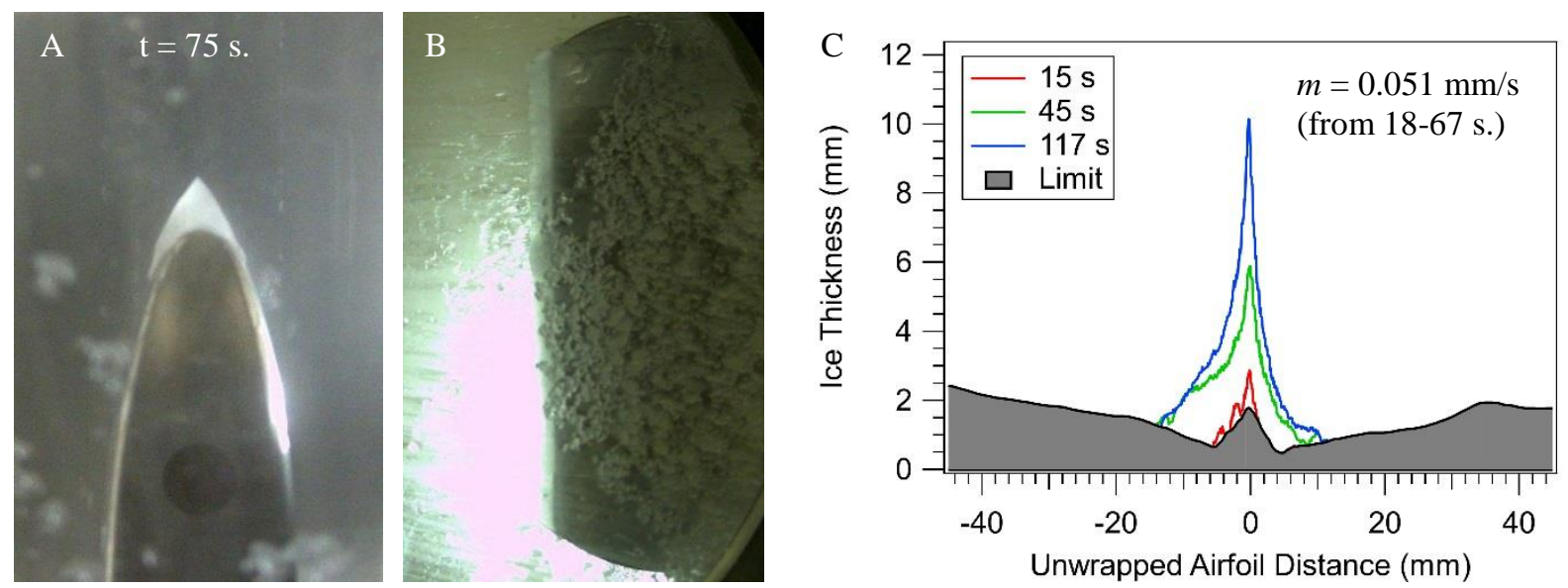

Figure 15. Ice shapes $(A$ and $B)$ and $2 D$ profile accretion analysis $(C)$ for Test Point 2.07, Scan $942\left(M=0.4, T_{0}=15^{\circ} C, P_{0}=5\right.$ psia, small PSD, $T w b_{0}=0^{\circ} \mathrm{C}$ ) after 75 seconds of accretion. 

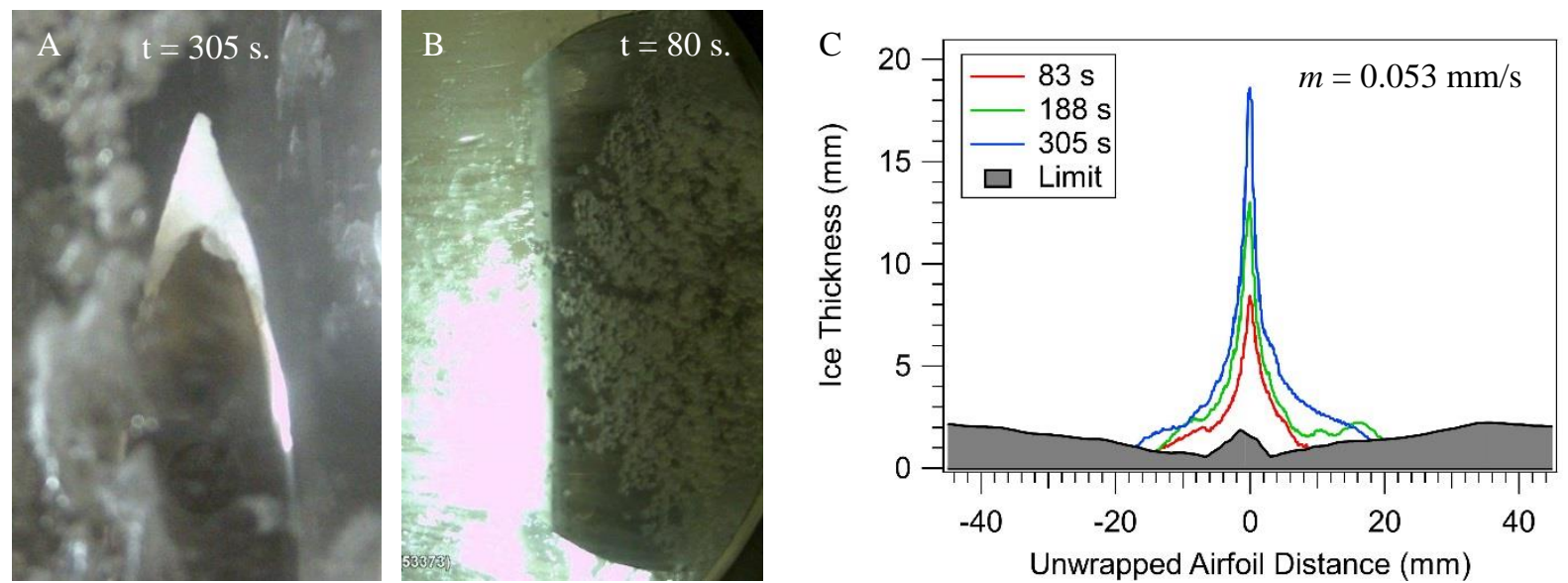

Figure 16. Ice shapes $(A$ and $B)$ and $2 D$ profile accretion analysis $(C)$ for Test Point $2.08, S c a n 944\left(M=0.4, T_{0}=15^{\circ} C, P_{0}=5\right.$ psia, small PSD, $\left.T w b_{0}=-0.4{ }^{\circ} \mathrm{C}\right)$. The left image (2D profile view) shows the accretion after 305 seconds of accretion. The middle image (span view) shows the accretion after $\sim 80$ seconds of accretion (the view became obscured shortly afterwards).
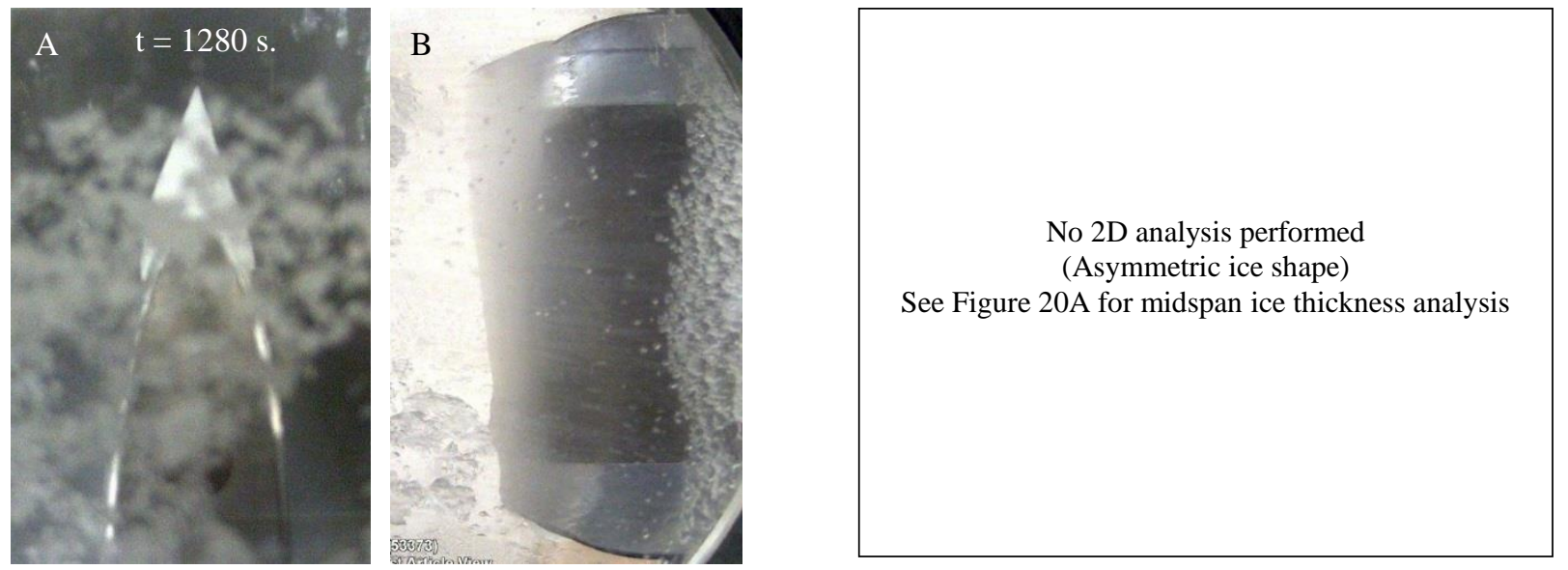

Figure 17. Ice shapes ( $A$ and $B$ ) for Test Point 3.01, Scan $954\left(M=0.4, T_{0}=15^{\circ} \mathrm{C}, P_{0}=5\right.$ psia, small PSD, $\operatorname{Twb}_{0}=0.0^{\circ} \mathrm{C}$, TWC varies during the test) after 1280 seconds of accretion at an increasing TWC. 

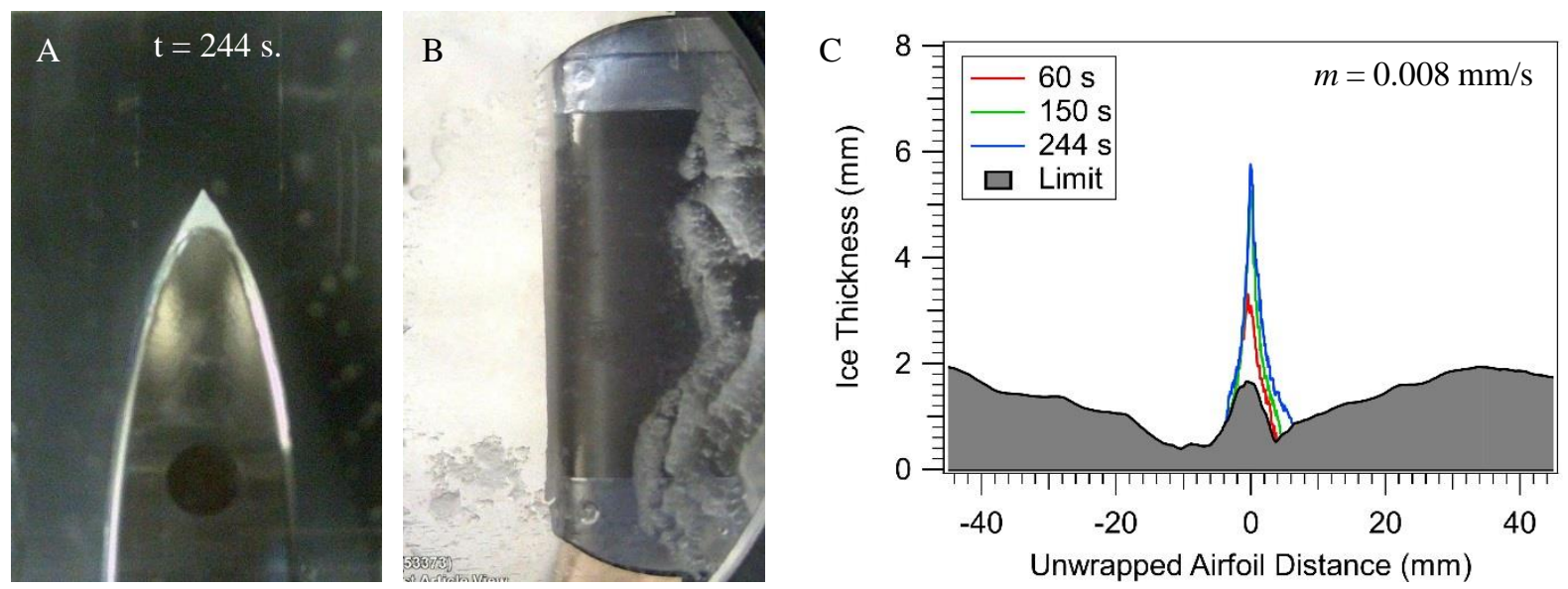

Figure 18. Ice shapes $(A$ and $B)$ and $2 D$ profile accretion analysis $(C)$ for Test Point 3.02, Scan $956\left(M=0.4, T_{0}=15^{\circ} C, P_{0}=5\right.$ psia, small PSD, $T w b_{0}=0.0^{\circ} \mathrm{C}, T W C=3 \mathrm{~g} / \mathrm{m}^{3}$ ) after $\sim 244$ seconds of accretion.
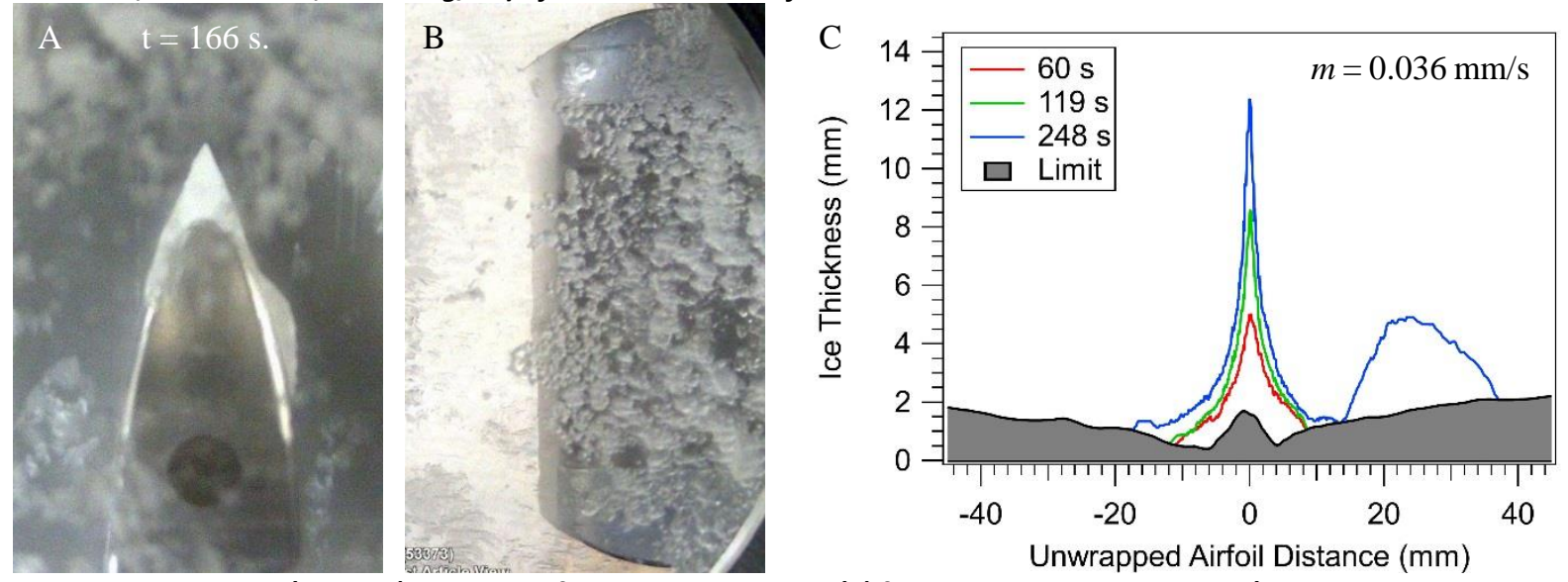

Figure 19. Ice shapes $(A$ and $B)$ and $2 D$ profile accretion analysis $(C)$ for Test Point 3.03, Scan $958\left(M=0.4, T_{0}=15^{\circ} C, P_{0}=5\right.$ psia, small PSD, $T w b_{0}=0.0^{\circ} \mathrm{C}, T W C=6 \mathrm{~g} / \mathrm{m}^{3}$ ) after $\sim 166$ seconds of accretion.
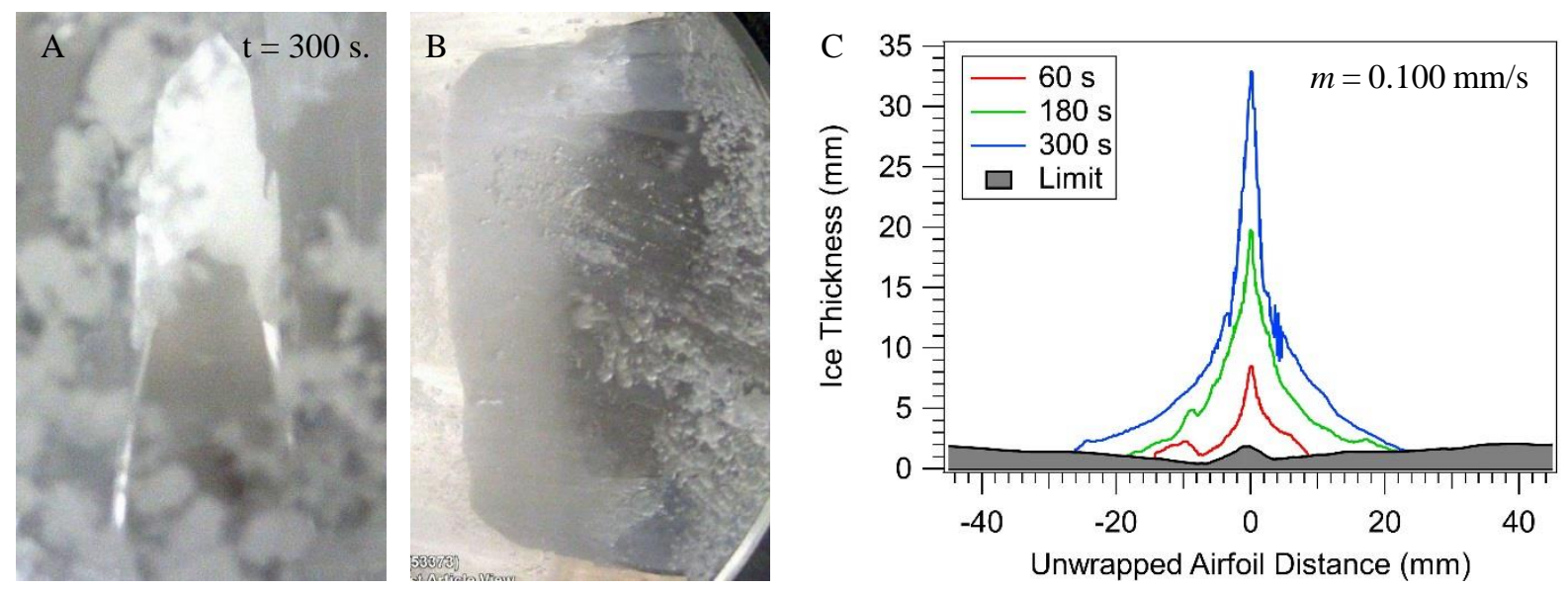

Figure 20. Ice shapes ( $A$ and $B)$ and $2 D$ profile accretion analysis $(C)$ for Test Point 3.11, Scan $960\left(M=0.4, T_{0}=15^{\circ} C, P_{0}=5\right.$ psia, small PSD, $T w b_{0}=0.0^{\circ} \mathrm{C}, T W C=10 \mathrm{~g} / \mathrm{m}^{3}$ ) after $\sim 300$ seconds of accretion. 


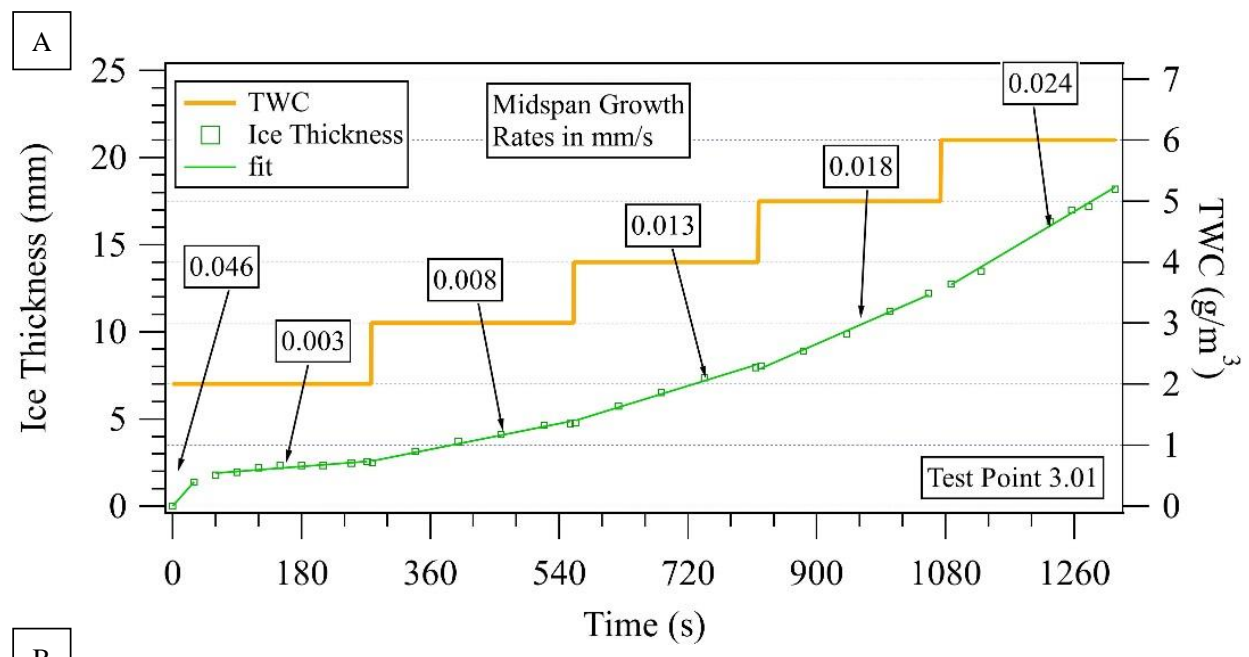

$\mathrm{B}$

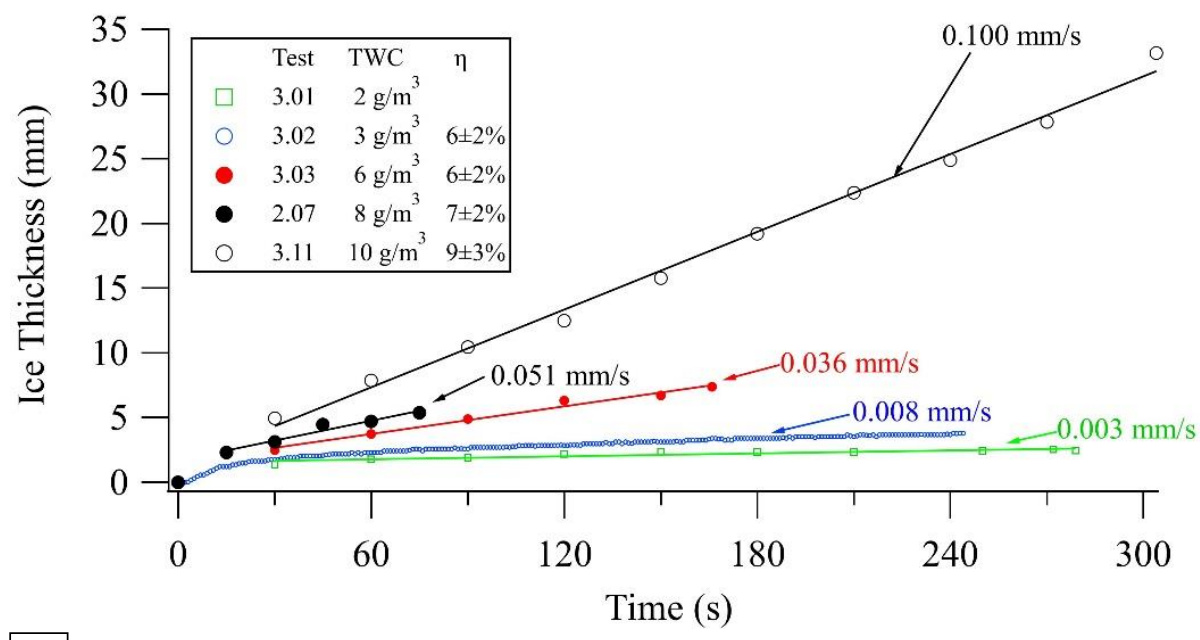

$\mathrm{C}$

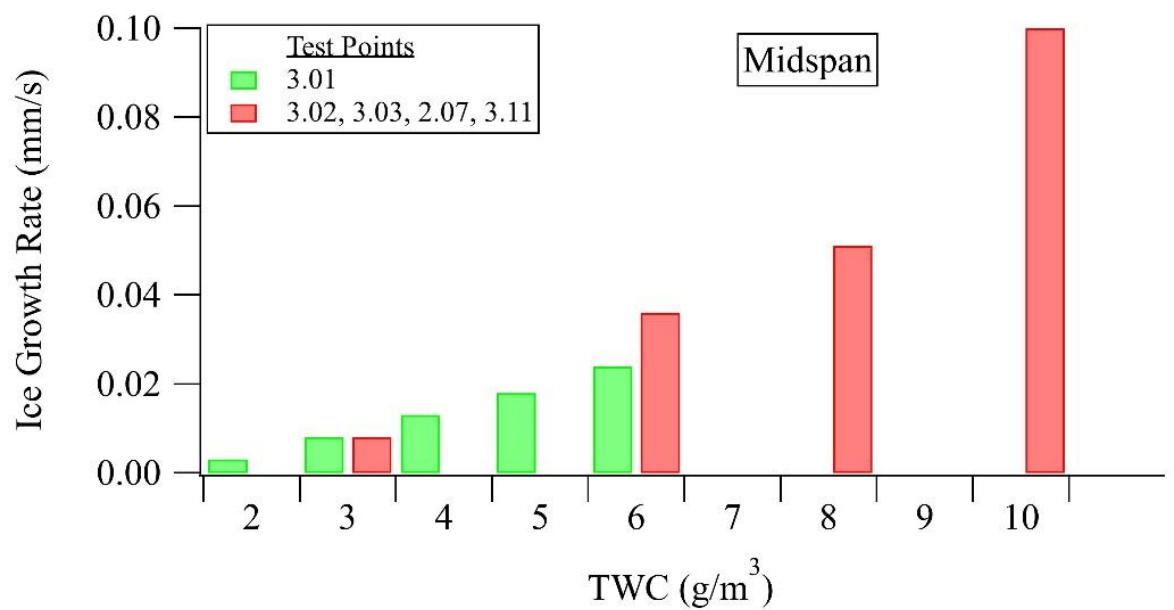

Figure 21. Ice thickness vs. time (graphs $A$ and B) for the TWC variation tests. During Test Point 3.01, the TWC was varied incrementally during the same spray while the TWC was maintained constant during the other test points. The measured melt ratio, $\eta$, is included in the legend of (B). The bar chart $(C)$ compares the ice growth rates vs TWC from all of the tests.

American Institute of Aeronautics and Astronautics 


\section{Tables}

\begin{tabular}{|c|c|c|c|c|c|c|c|c|c|c|c|c|c|c|c|c|c|}
\hline 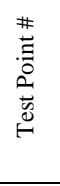 & Test Objective & $\begin{array}{l}0 \\
.3 \\
0 \\
0 \\
0 \\
0\end{array}$ & $\stackrel{\leftrightarrow}{\ominus}$ & $\begin{array}{l}\text { U } \\
\text { 兘 } \\
\text { E } \\
\text { ही }\end{array}$ & $\begin{array}{l}\vec{U} \\
\tilde{0} \\
E \\
\text { E } \\
E\end{array}$ & 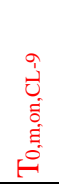 & : & $\vec{e}^{+}$ & $\stackrel{\ominus}{\Sigma}$ & 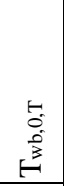 & $\begin{array}{l}\text { \& } \\
\vdots \\
0 \\
0 \\
0 \\
E\end{array}$ & $\begin{array}{l}\text { 己 } \\
\dot{0} \\
\dot{E} \\
0 \\
0 \\
\dot{B}\end{array}$ & $\begin{array}{l}\hat{I} \\
\dot{U} \\
\tilde{\Xi} \\
\dot{\Xi} \\
0 \\
\dot{B} \\
\dot{B}\end{array}$ & $\frac{5}{\sqrt{n}}$ & 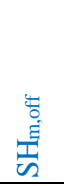 & $\begin{array}{l}\vec{U} \\
\tilde{E} \\
\tilde{E} \\
\text { 剖 }\end{array}$ & 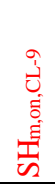 \\
\hline & Units $\rightarrow$ & $\#$ & ${ }^{\circ} \mathrm{C}$ & ${ }^{\circ} \mathrm{C}$ & ${ }^{\circ} \mathrm{C}$ & ${ }^{\circ} \mathrm{C}$ & PSIA & PSIA & - & ${ }^{\circ} \mathrm{C}$ & ${ }^{\circ} \mathrm{C}$ & ${ }^{\circ} \mathrm{C}$ & ${ }^{\circ} \mathrm{C}$ & $\mathrm{g} / \mathrm{kg}$ & $\mathrm{g} / \mathrm{kg}$ & $\mathrm{g} / \mathrm{kg}$ & $\mathrm{g} / \mathrm{kg}$ \\
\hline 1.00 & Low Mach, Large PSD, Twb0 $=6^{\circ} \mathrm{C}$ & $\mathrm{A}, \mathrm{B}$ & 15.0 & 14.9 & 10.7 & 11.1 & 5.0 & 4.8 & 0.25 & 6.0 & 5.9 & 6.5 & 6.7 & 15 & 13.5 & 16.0 & 16.2 \\
\hline 1.02 & Low Mach, Large PSD, Twb $0=3^{\circ} \mathrm{C}$ & $\mathrm{A}, \mathrm{B}$ & 15.0 & 15.2 & 9.2 & 9.0 & 5.0 & 4.8 & 0.25 & 3.0 & 3.7 & 4.3 & 4.3 & 10 & 10.2 & 13.3 & 13.3 \\
\hline 1.04 & Low Mach, Large PSD, Lowest Humidity & $\mathrm{A}$ & 15.0 & 13.9 & 8.2 & 8.3 & 5.0 & 4.8 & 0.25 & -5.2 & 0.6 & 2.1 & 2.2 & 0 & 6.5 & 10.8 & 10.9 \\
\hline 1.07 & Low Mach, Small PSD, Twb0 $=3^{\circ} \mathrm{C}$ & $\mathrm{A}$ & 15.0 & 14.6 & 2.5 & 2.8 & 5.0 & 4.8 & 0.25 & 3.0 & 2.9 & 2.1 & 2.4 & 10 & 9.4 & 12.8 & 13.1 \\
\hline 1.08 & Low Mach, Small PSD, Twb0 $=0^{\circ} \mathrm{C}$ & $\mathrm{A}$ & 15.0 & 14.5 & 1.7 & 2.1 & 5.0 & 4.8 & 0.25 & 0.0 & 0.4 & 1.1 & 1.4 & 6 & 6.4 & 11.9 & 12.1 \\
\hline 1.09 & Low Mach, Small PSD, Lowest Humidity & $\mathrm{A}$ & 15.0 & 14.9 & -1.7 & -1.2 & 5.0 & 4.8 & 0.25 & -5.2 & -2.9 & -2.4 & -1.8 & 0 & 2.6 & 9.1 & 9.6 \\
\hline 2.00 & High Mach, Large PSD, Twb0 $=6^{\circ} \mathrm{C}$ & A & 15.0 & 15.0 & & 11.8 & 5.0 & 4.5 & 0.40 & 6.0 & 5.7 & & 5.9 & 15 & 13.3 & & 14.7 \\
\hline 2.01 & High Mach, Large PSD, Twb0 $=3^{\circ} \mathrm{C}$ & A & 15.0 & 15.7 & & 11.3 & 5.0 & 4.5 & 0.40 & 3.0 & 2.2 & & 2.4 & 10 & 8.5 & & 10.1 \\
\hline 2.02 & High Mach, Large PSD, Twb0 $=0^{\circ} \mathrm{C}$ & A & 15.0 & 15.7 & & 11.4 & 5.0 & 4.5 & 0.40 & 0.0 & -0.5 & & -0.2 & 6 & 4.9 & & 6.8 \\
\hline 2.03 & High Mach, Large PSD, Lowest Humidity & $\mathrm{A}$ & 15.0 & 15.1 & & 9.2 & 5.0 & 4.5 & 0.40 & -5.2 & -3.4 & & -3.8 & 0 & 2.2 & & 3.7 \\
\hline 2.05 & High Mach, Small PSD, Twb0 $=6^{\circ} \mathrm{C}$ & A & 15.0 & 15.8 & & 7.9 & 5.0 & 4.5 & 0.40 & 6.0 & 5.9 & & 5.5 & 15 & 13.7 & & 15.8 \\
\hline 2.06 & High Mach, Small PSD, Twb0 $=3^{\circ} \mathrm{C}$ & $\mathrm{A}$ & 15.0 & 15.2 & & 6.9 & 5.0 & 4.5 & 0.40 & 3.0 & 3.4 & & 3.5 & 10 & 10.2 & & 13.3 \\
\hline 2.07 & High Mach, Small PSD, Twb0 $=0^{\circ} \mathrm{C}$ & A & 15.0 & 14.3 & & 4.9 & 5.0 & 4.5 & 0.40 & 0.0 & 0.1 & & 0.9 & 6 & 6.1 & & 10.3 \\
\hline 2.08 & High Mach, Small PSD, Lowest Humidity & A & 15.0 & 15.2 & & 5.5 & 5.0 & 4.5 & 0.40 & -5.2 & -0.4 & & 1.0 & 0 & 5.1 & & 10.3 \\
\hline 3.00 & Repeat Point (TP \#2.07) & A & 15.0 & 15.6 & 6.4 & 7.1 & 5.0 & 4.5 & 0.40 & 0.0 & -0.8 & 0.4 & 0.3 & 6 & 4.5 & 9.0 & 8.6 \\
\hline 3.01 & Capture TWC threshold for accretion. & $\mathrm{C}$ & 15.0 & 15.5 & & 7.1 & 5.0 & 4.5 & 0.40 & 0.0 & -0.1 & & 0.7 & 6 & 5.2 & & 9.2 \\
\hline 3.02 & $\mathrm{IWCi}=3 \mathrm{~g} / \mathrm{m} 3$ & $\mathrm{C}$ & 15.0 & 14.8 & 8.3 & 8.7 & 5.0 & 4.5 & 0.40 & 0.0 & -0.2 & 0.3 & 0.3 & 6 & 5.4 & 8.4 & 8.3 \\
\hline 3.03 & $\mathrm{IWCi}=6 \mathrm{~g} / \mathrm{m} 3$ & $\mathrm{C}$ & 15.0 & 14.5 & 6.8 & 7.0 & 5.0 & 4.5 & 0.40 & 0.0 & -0.2 & 0.6 & 0.6 & 6 & 5.6 & 9.3 & 9.2 \\
\hline 3.11 & IWCi $=10 \mathrm{~g} / \mathrm{m} 3$ & $\mathrm{C}$ & 15.0 & 14.6 & 7.4 & 8.4 & 5.0 & 4.5 & 0.40 & 0.0 & 0.5 & 2.1 & 2.5 & 6 & 6.3 & 10.8 & 10.8 \\
\hline 3.06 & MW False Response, M=0.4, Large PSD & $\mathrm{D}$ & -5.0 & -17.5 & & -18.2 & 5.0 & 4.5 & 0.40 & -14.0 & -19.6 & & -19.4 & 0 & 1.7 & & 1.9 \\
\hline 3.07 & MW False Response, M=0.4, Small PSD & $\mathrm{D}$ & -5.0 & -12.9 & & -16.2 & 5.0 & 4.5 & 0.40 & -14.0 & -17.2 & & -17.5 & 0 & 2.1 & & 2.3 \\
\hline 3.09 & MW False Response, $\mathrm{M}=0.25$, Small PSD & $\mathrm{D}$ & -5.0 & -5.8 & & -14.6 & 5.0 & 4.8 & 0.25 & -14.0 & -13.8 & & -15.2 & 0 & 3.4 & & 3.2 \\
\hline 3.08 & MW False Response, M=0.25, Large PSD & $\mathrm{D}$ & -5.0 & -5.8 & & -14.6 & 5.0 & 4.8 & 0.25 & -14.0 & -18.2 & & -16.9 & 0 & 1.0 & & 2.3 \\
\hline
\end{tabular}

Table 1. Test matrix with target and measured aerothermal conditions. Objectives refer to the subsections in Section III. Blank table entries denote cases where the TAT \& RH probe malfunctioned preventing centerline measurements from being taken.

American Institute of Aeronautics and Astronautics 


\begin{tabular}{|c|c|c|c|c|c|c|c|c|c|c|c|c|}
\hline 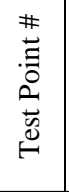 & Test Objective & $\underbrace{E}_{E}$ & 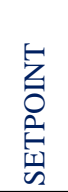 & $\begin{array}{l}\text { 至 } \\
U \\
3\end{array}$ & $\begin{array}{l}\vec{i} \\
\bigcup_{3}\end{array}$ & $\begin{array}{l}n \\
0 \\
3 \\
3 \\
3\end{array}$ & 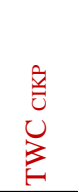 & $\hat{\tilde{2}}$ & & $\overrightarrow{\mathrm{i}}$ & & $\stackrel{n}{\stackrel{\varepsilon}{\varepsilon}}$ \\
\hline & Units $\rightarrow$ & $\mathrm{g} / \mathrm{m}^{3}$ & $\mathrm{pph}$ & $\mathrm{g} / \mathrm{m}^{3}$ & $\mathrm{~g} / \mathrm{m}^{3}$ & $\mathrm{~g} / \mathrm{m}^{3}$ & $\mathrm{~g} / \mathrm{m}^{3}$ & - & & - & & - \\
\hline 1.00 & Low Mach, Large PSD, Twb0 $=6^{\circ} \mathrm{C}$ & 8.0 & 180 & 2.9 & 0.9 & 1.2 & 9.6 & Large & 0.05 & \pm 0.03 & 0.08 & \pm 0.03 \\
\hline 1.02 & Low Mach, Large PSD, Twb0 $=3^{\circ} \mathrm{C}$ & 8.0 & 180 & 2.9 & 0.7 & 0.9 & 7.6 & Large & 0.04 & \pm 0.02 & 0.07 & \pm 0.03 \\
\hline 1.04 & Low Mach, Large PSD, Lowest Humidity & 8.0 & 180 & 2.7 & 0.4 & 0.7 & 7.6 & Large & -0.01 & \pm 0.01 & 0.03 & \pm 0.02 \\
\hline 1.07 & Low Mach, Small PSD, Twb0 $=3^{\circ} \mathrm{C}$ & 8.0 & 245 & 5.0 & 1.4 & 1.6 & 8.3 & Small & 0.22 & \pm 0.08 & 0.23 & \pm 0.08 \\
\hline 1.08 & Low Mach, Small PSD, Twb0 $=0^{\circ} \mathrm{C}$ & 8.0 & 245 & 4.7 & 0.9 & 0.9 & 7.6 & * Small & 0.15 & \pm 0.06 & 0.13 & \pm 0.05 \\
\hline 1.09 & Low Mach, Small PSD, Lowest Humidity & 8.0 & 245 & 5.0 & 0.6 & 0.7 & 8.5 & Small & 0.07 & \pm 0.03 & 0.08 & \pm 0.03 \\
\hline 2.00 & High Mach, Large PSD, Twb0 $=6^{\circ} \mathrm{C}$ & 8.0 & 175 & 3.9 & 0.7 & 1.0 & 7.6 & * Large & 0.09 & \pm 0.03 & 0.14 & \pm 0.04 \\
\hline 2.01 & High Mach, Large PSD, Twb $0=3^{\circ} \mathrm{C}$ & 8.0 & 175 & 3.4 & 0.4 & 0.6 & 7.2 & Large & 0.03 & \pm 0.01 & 0.06 & \pm 0.02 \\
\hline 2.02 & High Mach, Large PSD, Twb0 $=0^{\circ} \mathrm{C}$ & 8.0 & 175 & 3.1 & 0.2 & 0.4 & 7.3 & $*$ Large & 0.00 & \pm 0.01 & 0.02 & \pm 0.01 \\
\hline 2.03 & High Mach, Large PSD, Lowest Humidity & 8.0 & 175 & 2.9 & 0.2 & 0.4 & 7.6 & Large & -0.01 & \pm 0.01 & 0.01 & \pm 0.01 \\
\hline 2.05 & High Mach, Small PSD, Twb0 $=6^{\circ} \mathrm{C}$ & 8.0 & 260 & 5.2 & 1.5 & 1.7 & 7.5 & Small & 0.24 & \pm 0.09 & 0.26 & \pm 0.09 \\
\hline 2.06 & High Mach, Small PSD, Twb0 $=3^{\circ} \mathrm{C}$ & 8.0 & 260 & 4.2 & 1.0 & 1.1 & 8.1 & Small & 0.13 & \pm 0.05 & 0.14 & \pm 0.05 \\
\hline 2.07 & High Mach, Small PSD, Twb0 $=0^{\circ} \mathrm{C}$ & 8.0 & 260 & 4.2 & 0.6 & 0.7 & 7.8 & Small & 0.06 & \pm 0.03 & 0.07 & \pm 0.02 \\
\hline 2.08 & High Mach, Small PSD, Lowest Humidity & 8.0 & 260 & 3.8 & 0.6 & 0.7 & 7.2 & Small & 0.07 & \pm 0.03 & 0.08 & \pm 0.03 \\
\hline 3.00 & Repeat Point (TP \#2.07) & 8.0 & 290 & 4.4 & 0.6 & 0.6 & 8.8 & Small & 0.04 & \pm 0.02 & 0.04 & \pm 0.02 \\
\hline 3.01 & Capture TWC threshold for accretion. & & & & & & & Small & & & & \\
\hline 3.02 & $\mathrm{IWCi}=3 \mathrm{~g} / \mathrm{m} 3$ & 3.0 & 105 & 2.0 & 0.2 & 0.2 & 2.6 & Small & 0.04 & \pm 0.02 & 0.06 & \pm 0.02 \\
\hline 3.03 & $\mathrm{IWCi}=6 \mathrm{~g} / \mathrm{m} 3$ & 6.0 & 210 & 3.5 & 0.4 & 0.5 & 6.0 & * Small & 0.05 & \pm 0.02 & 0.06 & \pm 0.02 \\
\hline 3.11 & $\mathrm{IWCi}=10 \mathrm{~g} / \mathrm{m} 3$ & 10.0 & 375 & 5.4 & 1.1 & 1.1 & 10.4 & $*$ Small & 0.09 & \pm 0.04 & 0.09 & \pm 0.03 \\
\hline 3.06 & MW False Response, M=0.4, Large PSD & 8.0 & 175 & 3.7 & 0.3 & 0.4 & 9.5 & Large & 0.00 & \pm 0.01 & 0.00 & \pm 0.01 \\
\hline 3.07 & MW False Response, $\mathrm{M}=0.4$, Small PSD & 8.0 & 260 & 4.2 & 0.4 & 0.4 & 9.9 & * Small & 0.00 & \pm 0.01 & 0.00 & \pm 0.01 \\
\hline 3.09 & MW False Response, M=0.25, Small PSD & 8.0 & 245 & 5.3 & 0.6 & 0.7 & 10.2 & Small & 0.00 & \pm 0.01 & 0.00 & \pm 0.02 \\
\hline 3.08 & MW False Response, $\mathrm{M}=0.25$, Large PSD & 8.0 & 175 & 3.3 & 0.2 & 0.3 & 11.7 & Large & 0.00 & \pm 0.00 & 0.00 & \pm 0.01 \\
\hline
\end{tabular}

Table 2. Test matrix with target and measured cloud conditions as well as melt ratio ( $\eta$ ) estimates.

\begin{tabular}{|c|c|c|c|c|c|c|c|c|c|c|c|c|}
\hline $\begin{array}{l}\text { Test } \\
\text { Point }\end{array}$ & $\begin{array}{c}\text { DAS } \\
\#\end{array}$ & $M$ & PSD & $\begin{array}{c}T_{0, m, o n, C L-9} \\
\left({ }^{\circ} \mathrm{C}\right)\end{array}$ & $\begin{array}{l}T_{w b} \\
\left({ }^{\circ} \mathrm{C}\right) \\
\end{array}$ & $\begin{array}{c}L W C_{m, 2.1} \\
\left(\mathrm{~g} / \mathrm{m}^{3}\right)\end{array}$ & $\begin{array}{c}L W C_{m, 0.5} \\
\left(\mathrm{~g} / \mathrm{m}^{3}\right)\end{array}$ & $\begin{array}{c}T W C_{C I K P} \\
\left(\mathrm{~g} / \mathrm{m}^{3}\right)\end{array}$ & $C E_{083}$ & $C E_{021}$ & $\begin{array}{c}F R_{083} \\
(\%)\end{array}$ & $\begin{array}{c}F R_{021} \\
(\%)\end{array}$ \\
\hline 3.06 & 948 & 0.40 & Large & -18.2 & -19.4 & 0.28 & 0.37 & 9.30 & 0.992 & 0.994 & 3.06 & 3.98 \\
\hline 3.07 & 946 & 0.40 & Small & -16.2 & -17.5 & 0.38 & 0.43 & 9.94 & 0.969 & 0.979 & 3.91 & 4.43 \\
\hline 3.08 & 976 & 0.25 & Small & -14.6 & -15.2 & 0.62 & 0.73 & 10.07 & 0.988 & 0.991 & 2.03 & 2.81 \\
\hline 3.09 & 977 & 0.25 & Large & -14.6 & -16.9 & 0.23 & 0.32 & 11.52 & 0.959 & 0.973 & 6.43 & 7.41 \\
\hline
\end{tabular}

Table 3. Data used to calculate the SEA Multi-Element probe false response. The total temperature is cold to prevent any melting of the ice-crystal cloud.

\begin{tabular}{|l|c|c|c|c|c|}
\hline Parameter $\rightarrow$ & $\boldsymbol{L W C}_{\boldsymbol{m}} \mathbf{I s , *}^{*}$ & $\boldsymbol{C E}^{*}$ & $\boldsymbol{W E}^{*}$ & $\boldsymbol{F R}^{*}$ & $\boldsymbol{T W C}_{\boldsymbol{m}, \boldsymbol{C I K} \boldsymbol{P}^{6,31}}$ \\
\hline Uncertainty $\rightarrow$ & $10 \%$ & $5 \%$ & $33 \%$ & $10 \%$ & $3 \%$ \\
\hline
\end{tabular}

Table 4. Uncertainty estimates for the various parameters used to calculate melt ratio. The values are percent of measurement. The sources of the uncertainty, when available, are referenced in the table above or are estimated $\left({ }^{*}\right)$ by the authors. 


\begin{tabular}{|c|c|c|c|c|c|c|c|c|c|c|c|c|c|c|c|c|c|}
\hline 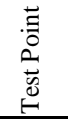 & & 完 & 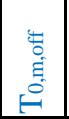 & 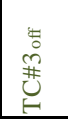 & 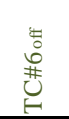 & 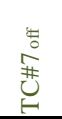 & 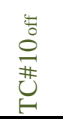 & 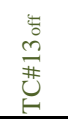 & 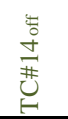 & 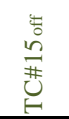 & 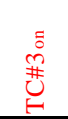 & 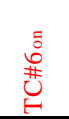 & 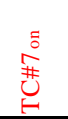 & 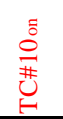 & 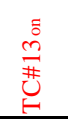 & 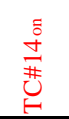 & 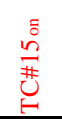 \\
\hline & Units $\rightarrow$ & \begin{tabular}{|c|}
${ }^{\circ} \mathrm{C}$ \\
\end{tabular} & \begin{tabular}{|c|}
${ }^{\circ} \mathrm{C}$ \\
\end{tabular} & ${ }^{\circ} \mathrm{C}$ & ${ }^{\circ} \mathrm{C}$ & ${ }^{\circ} \mathrm{C}$ & ${ }^{\circ} \mathrm{C}$ & ${ }^{\circ} \mathrm{C}$ & ${ }^{\circ} \mathrm{C}$ & ${ }^{\circ} \mathrm{C}$ & ${ }^{\circ} \mathrm{C}$ & ${ }^{\circ} \mathrm{C}$ & ${ }^{\circ} \mathrm{C}$ & ${ }^{\circ} \mathrm{C}$ & ${ }^{\circ} \mathrm{C}$ & ${ }^{\circ} \mathrm{C}$ & ${ }^{\circ} \mathrm{C}$ \\
\hline 1.00 & Low Mach, Large PSD, Twbo $=6$ & 15.0 & 14.9 & 15.6 & 15.4 & 15.4 & 15.5 & 15.5 & 15.7 & 15.6 & 0.1 & 0.5 & 1.9 & 3.1 & 4.6 & 4.8 & 6.1 \\
\hline 1.02 & Low Mach, Large PSD, Twbo = 3 & 15.0 & 15.2 & 15.2 & 15.2 & 15.1 & 15.2 & 15.2 & 15.5 & 15.3 & 0.1 & 0.6 & 1.6 & 3.4 & 5.8 & 7.1 & 8.4 \\
\hline 1.04 & Low Mach, Lar & 15.0 & 13.9 & 14.9 & 14.8 & 14.5 & 14.7 & 14.6 & 14.9 & 14.6 & 0.1 & 0.3 & 3.1 & 6.0 & 7.5 & 9.2 & 10.0 \\
\hline 1.07 & Low Mach, Small Ps & 15.0 & 14.6 & 14.9 & 14.9 & 14.7 & 14.8 & 14.7 & 15.0 & 14. & 0.0 & 0.0 & -0.1 & 0.2 & 0.2 & 0.7 & 1.5 \\
\hline 1.08 & Low $\mathrm{M}$ & 15.0 & 14.5 & 14.9 & 14.8 & 14.5 & 14.7 & 14.5 & 14.7 & 14. & 0.0 & -0.1 & -0.5 & -0.5 & -0.5 & 0.3 & 3.5 \\
\hline 1.09 & Low M & 15.0 & \begin{tabular}{|l|}
14.9 \\
\end{tabular} & 15.2 & 15.0 & 14.8 & 14.9 & 14.8 & 15.0 & 14. & -2.2 & -2.8 & -3.3 & -2.9 & -2.8 & -1.8 & 1.9 \\
\hline 2.00 & & 15.0 & \begin{tabular}{|l|}
15.0 \\
\end{tabular} & 13.8 & 13.9 & 13.8 & 13.9 & 14.0 & 14.6 & 14. & 0.1 & 1.5 & 2.2 & 4.5 & 7.4 & 9.0 & 9.6 \\
\hline 2.01 & High & 15.0 & 15.7 & 15.0 & 14.7 & 14.3 & 14.4 & 14.5 & 15.1 & 15.1 & 0.0 & 0.0 & 1.4 & 5.4 & 7.7 & 10.0 & 10.6 \\
\hline 2.02 & High $\mathrm{I}$ & 15.0 & \begin{tabular}{|l|}
15.7 \\
\end{tabular} & \begin{tabular}{|l|}
15.0 \\
\end{tabular} & 14.7 & 14.3 & 14.3 & 14.3 & 15.0 & 15.0 & -0.1 & -0.6 & 3.1 & 5.8 & 7.4 & 9.3 & 9.6 \\
\hline 2.03 & High $\mathrm{N}$ & 15.0 & \begin{tabular}{|l|}
15.1 \\
\end{tabular} & 14.1 & 13.4 & 13.1 & 13.1 & 13.1 & 13.7 & 13.6 & -2.8 & -1.0 & 2.7 & 4.8 & 5.8 & 7.2 & 8.4 \\
\hline 2.05 & High $\mathrm{N}$ & 15.0 & 15.8 & 15.6 & 15.0 & 14.8 & 14.8 & 14.9 & 15.4 & 14.9 & 0.0 & 0.0 & 1.1 & 1.9 & 2.5 & 3.1 & 3.4 \\
\hline 2.06 & High $\mathrm{N}$ & 15.0 & 15.2 & 15.0 & 14.5 & 14.1 & 14.3 & 14.3 & 14.8 & 14. & -0.1 & 0.1 & 0.0 & 0.2 & 0.4 & 0.7 & 1.6 \\
\hline 2.07 & High $\mathrm{M}$ & 15.0 & \begin{tabular}{|l|}
14.3 \\
\end{tabular} & 13.7 & 13.2 & 12.8 & 12.9 & 13.0 & 13.5 & 13. & 0.0 & -0.9 & 0.4 & 2.2 & 2.8 & 4.4 & 6.2 \\
\hline 2.08 & High Mach, Small PSD, Lowest Humidity & 15.0 & 15.2 & 15.0 & 14.7 & 14.2 & 14.2 & 14.3 & 14.7 & 14.5 & -0.2 & -0.9 & 0.2 & 2.0 & 2.6 & 3.7 & 4.8 \\
\hline 3.00 & & 15.0 & 15.6 & 14.9 & 14.3 & 14.1 & 14.1 & 14.1 & 14.6 & 14 & -0.2 & -1.4 & -0.1 & 1.6 & 2.4 & 3.7 & 5.4 \\
\hline $3.01 *$ & Capture TWC threshold for accretion. & 15.0 & 15.5 & 14.8 & 14.2 & 13.9 & 14.0 & 14.0 & 14.6 & 14.4 & -0.2 & -0.8 & 1.1 & 2.9 & 3.4 & 4.1 & 4.0 \\
\hline 3.02 & $\mathrm{IWCi}=3 \mathrm{~g} / \mathrm{m} 3$ & 15.0 & 14.8 & 14.3 & 13.7 & 13.5 & 13.5 & 13.5 & 14.1 & 14.0 & -0.4 & 0.3 & 2.8 & 4.3 & 5.1 & 6.6 & 7.7 \\
\hline 3.03 & $\mathrm{IWCi}=6 \mathrm{~g} / \mathrm{m} 3$ & 15.0 & 14.5 & 13.9 & 13.3 & 13.0 & 13.0 & 13.0 & 13.4 & 13.0 & -0.2 & -1.0 & 1.1 & 2.7 & 3.3 & 4.5 & 5.6 \\
\hline 3.11 & IWC $\mathrm{i}=10 \mathrm{~g} / \mathrm{m} 3$ & 15.0 & 14.6 & 14.3 & 13.7 & 13.5 & 13.5 & 13.5 & 14.0 & 13.7 & 0.0 & -0.3 & -0.7 & 0.8 & 1.7 & 2.3 & 3.3 \\
\hline 3.06 & & & -17.5 & -18.4 & -18.5 & -18.6 & -18.4 & -18.5 & -17.8 & -17.9 & -15.7 & -17.1 & -17.7 & -17.8 & -18.0 & -17.9 & -17.7 \\
\hline 3.07 & & -5.0 & -12.9 & -13.7 & -14.1 & -14.0 & -14.1 & -14.3 & -13.5 & -13.2 & -14.9 & -15.9 & -15.9 & -15.5 & -15.7 & -15.4 & -14.3 \\
\hline 3.09 & & -5.0 & \begin{tabular}{|l|}
-5.8 \\
\end{tabular} & \begin{tabular}{|l|}
-7.8 \\
\end{tabular} & -7.5 & -7.8 & -7.8 & -7.9 & -7.2 & -4.9 & -9.9 & -11.8 & -12.6 & -12.6 & -12.7 & -11.1 & -8.2 \\
\hline 3.08 & MW False Response, $\mathrm{M}=0.25$, Large PSD & -5.0 & -5.8 & -16.5 & -16.5 & -16.6 & -14.5 & -13.4 & -12.1 & -12.2 & -12.0 & -14.1 & -14.7 & -14.5 & -14.6 & -13.7 & -13.0 \\
\hline
\end{tabular}

Table 5. Thermocouple measurement results. 


\begin{tabular}{|c|c|c|c|c|c|c|c|c|c|c|c|c|}
\hline $\begin{array}{l}\text { Test } \\
\text { Point }\end{array}$ & Target & Instrument & $D v_{0.1}$ & $\mathrm{Dv}_{0.2}$ & $\mathrm{Dv}_{0.3}$ & $\mathrm{Dv}_{0.4}$ & $D v_{0.5}$ & $\mathrm{Dv}_{0.6}$ & $\mathrm{Dv}_{0.7}$ & $\mathrm{Dv}_{0.8}$ & $D v_{0.9}$ & $\mathrm{Dv}_{0.99}$ \\
\hline & Small & Target & 19 & & & & 28 & & & & 44 & \\
\hline & Large & Target & 31 & & & & 57 & & & & 126 & \\
\hline 1.00 & Large & PIV & 29 & 37 & 44 & 51 & 59 & 70 & 83 & 99 & 124 & 188 \\
\hline 1.02 & Large & PIV & 27 & 34 & 40 & 47 & 54 & 64 & 77 & 92 & 117 & 171 \\
\hline \multirow{2}{*}{1.04} & \multirow{2}{*}{ Large } & PIV & 27 & 33 & 40 & 46 & 54 & 63 & 76 & 92 & 118 & 182 \\
\hline & & $H S I^{*}$ & 18 & 23 & 29 & 34 & 40 & 47 & 55 & 65 & 77 & 114 \\
\hline 1.07 & Small & PIV & 17 & 23 & 27 & 31 & 34 & 38 & 43 & 50 & 62 & 157 \\
\hline 1.08 & Small & PIV & 15 & 20 & 24 & 27 & 31 & 35 & 40 & 46 & 58 & 101 \\
\hline 1.09 & Small & PIV & 15 & 21 & 25 & 29 & 32 & 36 & 41 & 47 & 60 & 101 \\
\hline
\end{tabular}

\begin{tabular}{|l|l|l|l|l|l|l|l|l|l|l|l|l|}
\hline 2.00 & Large & PIV & $\mathbf{2 9}$ & 37 & 44 & 50 & $\mathbf{5 8}$ & 67 & 80 & 93 & $\mathbf{1 1 6}$ & 165 \\
\hline 2.01 & Large & PIV & $\mathbf{2 9}$ & 37 & 43 & 50 & $\mathbf{5 8}$ & 68 & 80 & 93 & $\mathbf{1 1 6}$ & 175 \\
\hline 2.02 & Large & PIV & $\mathbf{3 4}$ & 43 & 50 & 58 & $\mathbf{6 6}$ & 77 & 87 & 100 & $\mathbf{1 2 4}$ & 180 \\
\hline 2.03 & Large & PIV & $\mathbf{3 1}$ & 39 & 47 & 54 & $\mathbf{6 1}$ & 73 & 84 & 98 & $\mathbf{1 2 0}$ & 174 \\
\hline 2.05 & Small & PIV & $\mathbf{1 5}$ & 20 & 24 & 28 & $\mathbf{3 1}$ & 35 & 40 & 47 & $\mathbf{5 8}$ & 101 \\
\hline 2.06 & Small & PIV & $\mathbf{1 6}$ & 21 & 25 & 28 & $\mathbf{3 2}$ & 35 & 41 & 48 & $\mathbf{6 0}$ & 100 \\
\hline 2.07 & Small & PIV & $\mathbf{1 6}$ & 21 & 25 & 29 & $\mathbf{3 3}$ & 37 & 42 & 49 & $\mathbf{6 1}$ & 114 \\
\hline 2.08 & Small & PIV & $\mathbf{1 6}$ & 21 & 25 & 29 & $\mathbf{3 3}$ & 37 & 42 & 49 & $\mathbf{6 2}$ & 106 \\
\hline
\end{tabular}

\begin{tabular}{|c|c|c|c|c|c|c|c|c|c|c|c|c|}
\hline 3.00 & Small & PIV & $\mathbf{1 6}$ & 22 & 27 & 31 & $\mathbf{3 5}$ & 40 & 45 & 52 & $\mathbf{6 6}$ & 94 \\
\hline 3.01 & Small & PIV & $\mathbf{1 4}$ & 18 & 22 & 26 & $\mathbf{3 0}$ & 34 & 39 & 46 & $\mathbf{5 6}$ & 89 \\
\hline \multirow{2}{*}{3.02} & \multirow{2}{*}{ Small } & PIV & $\mathbf{1 4}$ & 17 & 21 & 25 & $\mathbf{2 9}$ & 33 & 37 & 46 & $\mathbf{6 0}$ & 96 \\
& & $H_{S I}^{*}$ & $\mathbf{1 3}$ & $\mathbf{1 7}$ & 20 & 23 & $\mathbf{2 6}$ & 31 & 36 & 44 & $\mathbf{5 8}$ & 103 \\
\hline \multirow{2}{*}{3.03} & \multirow{2}{*}{ Small } & PIV & $\mathbf{1 5}$ & 20 & 24 & 28 & $\mathbf{3 2}$ & 36 & 41 & 48 & $\mathbf{6 0}$ & 106 \\
& & $H_{S I}^{*}$ & $\mathbf{1 5}$ & 18 & 22 & 25 & $\mathbf{2 9}$ & 33 & 40 & 48 & $\mathbf{6 2}$ & 97 \\
\hline \multirow{2}{*}{3.11} & \multirow{2}{*}{ Small } & PIV & $\mathbf{1 7}$ & 23 & 28 & 32 & $\mathbf{3 6}$ & 40 & 45 & 52 & $\mathbf{6 5}$ & 105 \\
& & HSI* & $\mathbf{1 5}$ & $\mathbf{1 7}$ & 20 & 22 & $\mathbf{2 5}$ & 29 & 34 & 42 & $\mathbf{5 6}$ & 93 \\
\hline
\end{tabular}

Table 6. Percentile cumulative volume diameter data for select test points from this test campaign. *Due to image obscuration issues, only select points from the HSI were analyzable and those results are shown for reference. The PIV data is recommended to be used for any future modelling of these results. 